\title{
Influence of different abiotic factors on lipid production by microalgae - a review
}

\author{
Clément Gaignard* ${ }^{*}$, George Zissis $(\mathbb{D}$ and David Buso \\ Université de Toulouse, LAPLACE UMR CNRS/INPT/UT3 5213, 118 route de Narbonne, Bât 3R3, 31062 Toulouse Cedex 9, France
}

Received 14 June 2021 - Accepted 15 November 2021

\begin{abstract}
Research on lipid production in microalgae, especially to target biofuels, has been widely published in recent decades. This literature is mostly focused on the optimization of culture conditions, metabolic engineering, biorefinery and downstream processes. At the lab scale, lipid production is very promising concerning biofuels production based on microalgae due to their high lipid content. However, the accumulation of knowledge associated with the development of processes and technologies for the production of biomass and associated lipids has so far not achieved the hoped-for commercial success due to still too expensive operating costs compared to fossil fuels. This review aims to present the influence of various abiotic factors on the accumulation of lipids and lipid profile in microalgae, such as the depletion of the culture medium, temperature and light, but also most innovative like the induction by hormones. Other optimization procedures and the use of wastewater to improve the cost-viability are discussed in perspective.
\end{abstract}

Keywords: microalgae / biodiesel / lipid production / abiotic factors

Résumé - Influence de différents facteurs abiotiques sur la production de lipides par les microalgues-une revue. Les recherches sur la production de lipides chez les microalgues, notamment à visé des biocarburants, ont été largement publiées ces dernières décennies. Cette littérature est principalement axée sur l'optimisation des conditions de culture, l'ingénierie métabolique, la bioraffinerie et les processus en aval. À l'échelle du laboratoire, la production des lipides à partir de microalgues pour la production de biocarburants est très prometteuse en raison de leur forte teneur en lipides. Cependant, l'accumulation de connaissances liées au développement de procédés et de technologies de production de biomasse et de lipides associés n'a jusqu'à présent pas atteint le succès commercial espéré en raison des coûts d'exploitation encore trop élevés par rapport aux énergies fossiles. Cette revue a pour objectif de présenter l'influence de divers facteurs abiotiques sur l'accumulation de lipides et le profil lipidique chez les microalgues, tels que l'épuisement du milieu de culture, la température et la lumière, mais aussi les plus innovants comme l'induction par les hormones. D'autres procédures d'optimisation et l'utilisation des eaux usées pour améliorer la rentabilité sont discutées en perspective.

Mots clés : microalgue / biocarburant / production lipidique / paramètres environnementaux

\section{Introduction}

Microalgae are photoautotrophic single cell-organisms capable to use solar energy, water, and inorganic nutrients to reduce $\mathrm{CO}_{2}$ into complex organic compounds. Their large diversity gives them the opportunity to live in diverse environments and is directly correlated to with a large variety of biomolecules such as amino acids, peptides, proteins, carbohydrates (oligo- and polysaccharides), lipid (polyunsaturated

\footnotetext{
it Contribution to the Topical Issue "Lipids from aquatic environments / Lipides issus des milieux aquatiques".

*Correspondence: clement.gaignard@laplace.univ-tlse.fr
}

fatty acids (PUFAs) and $\omega 3,-6)$ and pigments (Rajvanshi and Shankar Sagaram, 2019). The industrial exploitation of these metabolites on various commercial markets such pharmaceuticals, cosmetics, human food or feed is at its early stages, especially when it comes to biofuels. Usually biofuels can be classified as three generations: first generation corresponding to the feedstocks of food, second generation corresponding to lignocellulosic biomass and agricultural wastes and the third generation corresponding to photosynthetic microorganisms. Microalgae have gained more and more attention these last decades due to better characteristics compare to terrestrials plants, like fast growth rate, able to grow in lot of habitats, better $\mathrm{CO}_{2}$ capture compared to 
Table 1. Examples of the impact of nitrogen and phosphate on lipid production in some microalgae.

\begin{tabular}{|c|c|c|c|c|}
\hline Microalgae & Stress conditions & $\begin{array}{l}\text { Lipid content, } \\
\text { lipid productivity }\end{array}$ & Major lipids & References \\
\hline $\begin{array}{l}\text { Nannochloropsis oculata } \\
\text { NCTU-3 }\end{array}$ & Nitrogen depletion & $50.4 \%$, n.d & n.d & Chiu et al. (2009) \\
\hline $\begin{array}{l}\text { Scenedesmus obliquus } \\
\text { CNW-N }\end{array}$ & Nitrogen deprivation & $\begin{array}{l}38.9 \% \\
78.7 \mathrm{mg} . \mathrm{L}^{-1} . \mathrm{d}^{-1}\end{array}$ & $\begin{array}{l}\text { stearic acid }(\mathrm{C} 18: 0) \text {, oletic acid }(\mathrm{C} 18: 1) \text {, } \\
\text { palmitic acid }(\mathrm{C} 16: 0)\end{array}$ & Ho et al. (2010) \\
\hline $\begin{array}{l}\text { Chlorella vulgaris } \\
\text { ESP-31 }\end{array}$ & Nitrogen starvation & $\begin{array}{l}63.0 \% \\
51.2 \mathrm{mg} . \mathrm{L}^{-1} . \mathrm{d}^{-1}\end{array}$ & $\begin{array}{l}\text { palmitic acid }(\mathrm{C} 16: 0), \text { oletic acid } \\
(\mathrm{C} 18: 1) \text {, linoleic acid }(\mathrm{C} 18: 2)\end{array}$ & Yeh and Chang (2012) \\
\hline $\begin{array}{l}\text { Neochloris oleoabundans } \\
\text { HK-129 }\end{array}$ & Nitrogen starvation & $\begin{array}{l}27.2 \% \\
30.8 \mathrm{mg} . \mathrm{L}^{-1} . \mathrm{d}^{-1}\end{array}$ & $\begin{array}{l}\text { oletic acid (C18:1), palmitic acid } \\
(\mathrm{C} 16: 0) \text {, linoleic acid (C18:2) }\end{array}$ & Sun et al. (2014) \\
\hline $\begin{array}{l}\text { Scenedesmus sp. } \\
\text { LX1 }\end{array}$ & Nitrogen depletion & $33.0 \%$, n.d & n.d & Xin et al. (2010a) \\
\hline Chlorella zofingiensis & Nitrogen starvation & $\begin{array}{l}65.1 \% \\
87.1 \mathrm{mg} . \mathrm{L}^{-1} \cdot \mathrm{d}^{-1}\end{array}$ & n.d & Feng et al. (2012) \\
\hline Scenedesmus abundans & Phosphate starvation & $\begin{array}{l}23.0 \% \\
30.8 \mathrm{mg} . \mathrm{L}^{-1} . \mathrm{d}^{-1}\end{array}$ & $\begin{array}{l}\text { oletic acid (C18:1), palmitic acid } \\
(\mathrm{C} 16: 0) \text {, linoleic acid (C18:3) }\end{array}$ & Mandotra et al. (2016) \\
\hline
\end{tabular}

n.d: not determined

terrestrial plants induce by high-efficiency photosynthesis, high lipid content, smaller and non-arable surfaces. However, the economical barrier, due to high production cost compare to fossil energy, makes the commercialization of biofuel from microalgae unsuccessful. In order to improve cost-effective, various challenges must be took up all along the production process, from the selection of the strain, cultivation including environmental parameters and culture system, harvesting, drying, extraction and conversion of lipid. In nature, microalgae adapt to environmental changes with diverse and varied physiological responses. In view of this phenomenon, the culture conditions in which the microalgae are cultivated are very important to obtain higher lipid productivity. This review present a non-exhaustive list of abiotic factors that can be use to improve the lipid production as well as make change in lipid profile in microalgae.

\section{Nitrogen}

In microalgae, the most common solution to improve high lipid productivity, especially accumulation of TAG, was nitrogen starvation or $\mathrm{N}$-depleted condition. The strain was first cultivated with nutrient-rich medium to promote cell growth. During the growth phase, the microalgae will consume the nutrients from medium and tend naturally towards nitrogen deprivation to trigger lipid accumulation. Some examples are presented in Table 1.

As an example, in Nannochloropsis oculata NCTU-3 the lipid content during growth varying from $30.8 \%$ in logarithmic phase to $39.7 \%$ in early stationary phase and $50.4 \%$ at stationary phase (Chiu et al., 2009). In another study, a twostage nitrogen starvation strategy, composed of (1) growth under nutrient-rich conditions followed by (2) cultivation under nitrogen starvation was used on Neochloris oleoabundans HK-129. The total lipid and specific TAG productivities were increased by $29.6 \%$ and $67.7 \%$, respectively, compare to the single-stage (Sun et al., 2014). The quality of lipids is also impacted. Even if the lipid composition was similar, palmitic acid and oleic acid contents were 1.8 and 2 times higher in nutrient-deficient condition compared to the nutrient-rich condition in Scenedesmus obliquus CNW-N (Ho et al., 2010).

The nature of the nitrogen source can also influence the accumulation of intracellular lipids. Chlorella $\mathrm{sp}$. has shown the maximum lipid productivity of $0.124 \mathrm{~g} . \mathrm{L}^{-1} \cdot \mathrm{d}^{-1}$ with $0.100 \mathrm{~g} . \mathrm{L}^{-1}$ of urea in batch mode (Hsieh and $\left.\mathrm{Wu}, 2009\right)$. A semi-continuous process combining culture harvest and feeding urea each time the cultivation achieved the early stationary phase has led to the maximum lipid productivity, compared with batch and fed-batch.

Another example was the cultures of Schizochytrium sp. ABC101 in three types of fed-batch fermentations that used yeast extract as nitrogen source to regulate lipid accumulation. The limited nitrogen feeding provided the most efficient lipid production, with a maximum dry cell weight and lipids after $60 \mathrm{~h}$ (Ju et al., 2020). This production could be upgraded using corn sleep liquor (CSL) as nitrogen source, leading to a maximum dry cell weight and lipids after $84 \mathrm{~h}$. In addition, the CSL being less expensive than the yeast extract, its use made it possible to reduce by half the final cost of lipid production, which is particularly advantageous from the point of view of industrial production.

Stress from nitrogen starvation or N-depleted condition induce both overproduction of starch and lipids. The starch will be partially degraded and the lipid content will increase considerably. The accumulation of starch would then only be a temporary response to the environmental stress, while the accumulation of lipids could serve as long-term storage energy (Zhu et al., 2014). A study from Rai et al. (2017) on the longitudinal proteome dynamics of Chlorella sp. FC2 have confirmed that lipid accumulation was concomitant with 
Table 2. Examples of the impact of metallic trace elements on lipid production in some microalgae.

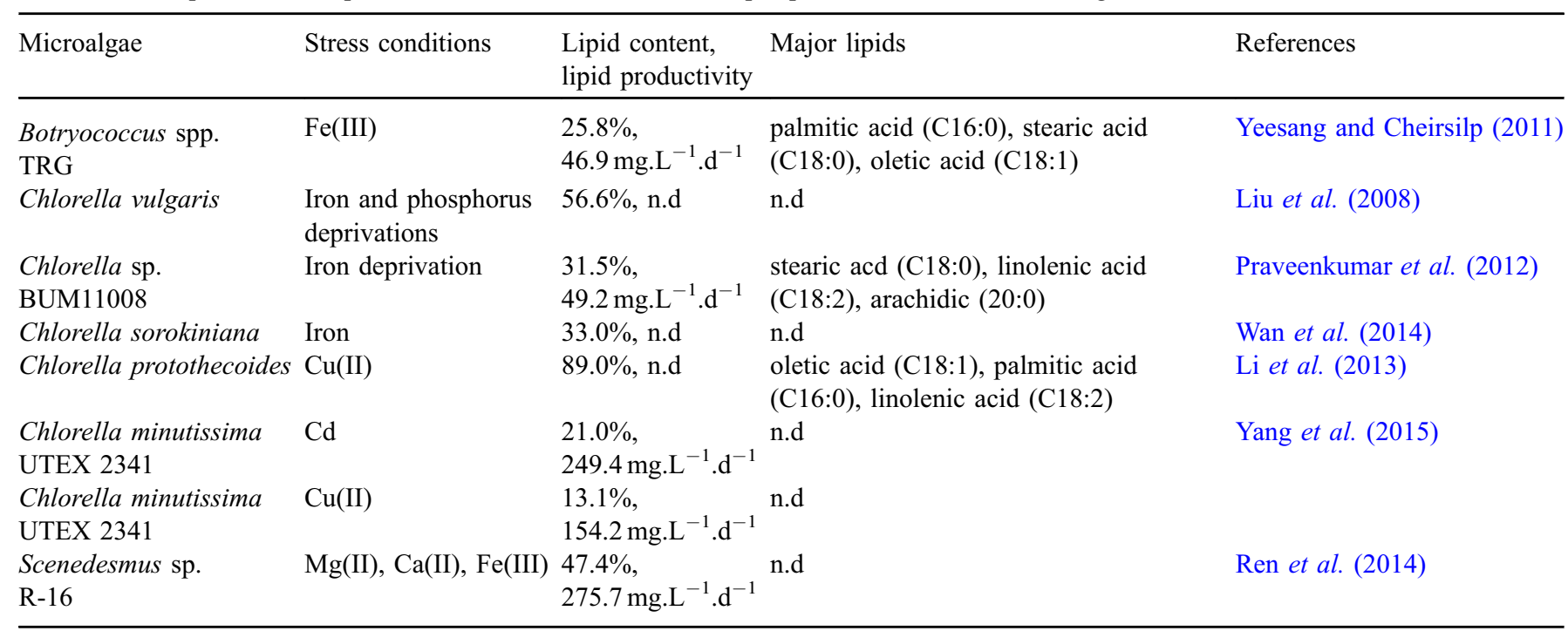

n.d: not determined

reduction in carbon flux towards carbohydrate, protein and chlorophyll biosynthesis, with a down-regulation of enzymes involved in chlorophyll biosynthesis (porphobilinogen deaminase) and photosynthetic carbon fixation (sedoheptulose-1,7 bisphosphate and phosphoribulokinase). Similar results were obtained in Chlorella PY-ZU1 with excess of phosphate and nitrogen deprivation, inducing a down-regulated of the chlorophyll biosynthesis metabolism and an up-regulation of several enzymes involved in carbon fixation via photosynthesis, oxidative phosphorylation, and glycerolipid metabolism which stimulated the biosynthesis (Chu et al., 2019).

Very recently, An et al. (2020) employed a new an unusual process based on addition of multiple small-doses of different forms of nitrogen to evaluated growth and lipid production in Scenedesmus obliquus. Compared to control, growth and lipid production have been promoted only by daily addition of $2 \mathrm{mg}$. $\mathrm{L}^{-1}$ of $\mathrm{NaNO}_{3}$ or $\mathrm{CH}_{4} \mathrm{~N}_{2} \mathrm{O}$. The highest yield of lipid production was obtained with $2 \mathrm{mg} . \mathrm{L}^{-1}$ of $\mathrm{CH}_{4} \mathrm{~N}_{2} \mathrm{O}$ (242.4 mg.L $\mathrm{L}^{-1}$ ), which is 2.75 times higher compare to the M-11 medium condition. Authors suggested that lipid accumulation observed under nitrogen starvation or depletion conditions could be at least partly mediated by oxidative stress. However, the connection between oxidative stress and increased microalgae lipid accumulation is not yet clearly defined, this understanding requires further investigation.

\section{Phosphate}

Like nitrogen deficiency, phosphorus starvation induces an accumulation of intracellular lipids in many microalgae (Tab. 1). For example, Mandotra et al. (2016) have studied impact of $\mathrm{K}_{2} \mathrm{HPO}_{4}$ concentrations on biomass, lipid concentration and fatty acid profile in Scenedesmus abundans. Among different phosphate concentrations, higher biomass productivity, lipid content and lipid productivity were obtained at $60 \mathrm{mg}$. $\mathrm{L}^{-1}$, follow by 80,40 and $20 \mathrm{mg} . \mathrm{L}^{-1}$. Furthermore, $60 \mathrm{mg} . \mathrm{L}^{-1}$ phosphate concentration was found to be most suitable for biofuel application. The amount of SFA (saturated fatty acids), MUFA (Monounsaturated fatty acids) and PUFA were $31.70 \%$, $48.35 \%$ and $19.95 \%$, respectively.

Study on Chlorella zofingiensis has shown that a medium enriched in nitrogen and phosphate provides better biomass production to the detriment of high lipid content. Depletion of the culture medium, in $\mathrm{P}$ or $\mathrm{N}$, made it possible to considerably improve the accumulation of intracellular lipids. However, the highest productivity was obtained from the $\mathrm{N}-\mathrm{P}+$ condition, indicating that nitrogen deficiency was more effective than phosphate deficiency for lipid accumulation (Feng et al., 2012).

As with nitrogen, phosphate deprivation can affect the quality of fatty acid content. For example, significant changes in the fatty acid and lipid composition of Monodus subterraneus were observed in phosphate deprivation condition by Khozin-Goldberg and Cohen (2006). With decreasing phosphate availability from 175 to 52.5 , then 17.5 and $0 \mu \mathrm{M}$, the proportion of eicosapentaenoic acid (EPA) gradually decreased from 28.2, 20.8, 19.4 and 15.5 (mol\% of total fatty acids), respectively. Similar results were obtained for monogalactosyldiacylglycerol (MGDG), digalactosyldiacylglycerol (DGDG), sulfoquinovosyldiacylglycerol (SQDG) and diacylglyceroltrimethylhomoserine (DGTS). At the opposite, the proportion of TAG was increased from 6.5 up to $39.3 \%$ of total lipids. The same type of deficiency induces also an accumulation of TAG in Chlamydomonas reinhardtii (Sato et al., 2014).

\section{Metallic trace elements}

Micronutrients and vitamins are elements of culture media present in very small amounts. They very rarely cause a deficiency in microalgae. Like macronutrients, they can also play an important role, acting on algal metabolic functions and increasing lipid content in microalgae as presented in Table 2. 
C. Gaignard et al.: OCL 2021, 28, 57

Table 3. Examples of the impact of carbon sources on lipid production in some microalgae.

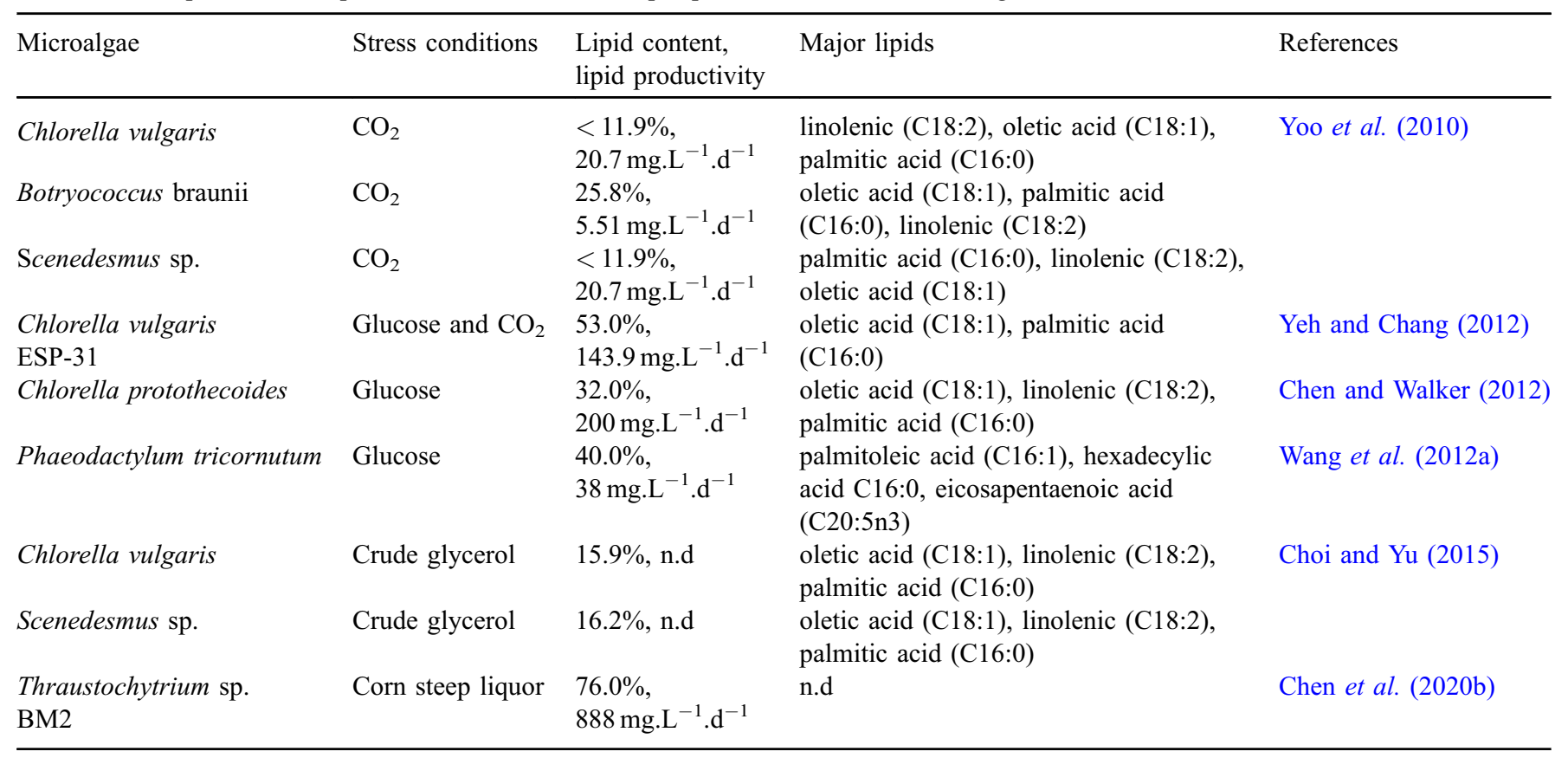

n.d: not determined

Iron $(\mathrm{Fe})$ is probably the most used metallic element. At high concentration, it is expected to increase lipid accumulation because of its down-regulation which requires fatty acid desaturase enzymes. As an example, replete Chlorella vulgaris in a fresh media supplemented with $1.2 \times 10^{-5}$ mol.L ${ }^{-1} \mathrm{Fe}^{3+}$ leading to a lipid content seven times higher than the controlled culture (Liu et al., 2008). A similar effect was observed in four Botryococcus strains by Yeesang and Cheirsilp (2011). The lipid content increased in all strains under both nitrogendeficient and nitrogen-rich conditions with increasing $\mathrm{Fe}^{3+}$ up to $0.037 \mathrm{mM}$, with highest lipid content for Botryococcus spp. TRG. This augmentation was more important in nitrogendeficient condition, probably due to a synergetic effect between iron and nitrogen deprivations.

Copper is an essential micronutrient found in some essential enzymes involved in metabolic pathways. Many studies have pointed out its beneficial effect on highly valuable component accumulation. Study about the impact of $\mathrm{Cu}$ (II) stress on Chlorella protothecoides was carried out by Li et al. (2013) using a two-steps process. The highest lipid content was achieved after $24 \mathrm{~h}$ induction by $31.4 \mathrm{mg} . \mathrm{L}^{-1} \mathrm{Cu}(\mathrm{II})$ which was 4-fold higher compare to the first heterotrophic stage. However, no difference in fatty acid composition was observed.

The effect of heavy metals on lipid production has been also investigated. For example, the use of 0.4 and $0.6 \mathrm{mM} \mathrm{Cd}$ significantly increases the lipid content of Chlorella minutissima UTEX 2341 by 93 and 42\%, respectively (Yang et al., 2015). The lipid productivity was increased for all conditions (except for 2 and $4 \mathrm{mM} \mathrm{Zn}$ and $4 \mathrm{mM} \mathrm{Mn}$ ). The higher lipid productivity was obtained by addition of $0.2 \mathrm{mM} \mathrm{Cd}$ followed by $0.6 \mathrm{mM} \mathrm{Cd}$ and $0.4 \mathrm{mM} \mathrm{Cu}$.

Different metal ions $\left(\mathrm{Fe}^{3+}, \mathrm{Mg}^{2+}\right.$ and $\left.\mathrm{Ca}^{2+}\right)$ were used to test their influence on Scenedesmus sp. R-16 growth and lipid accumulation. The maximum lipid productivity for $\mathrm{Mg}^{2+}$, $\mathrm{Ca}^{2+}$ and $\mathrm{Fe}^{3+}$ were obtained at $7.3 \times 10^{-3}, 9.8 \times 10^{-4}$ and $1.2 \times 10^{-3} \mathrm{~g} . \mathrm{L}^{-1}$, respectively. Moreover, addition of $1.0 \times 10^{-3}$ g. $\mathrm{L}^{-1}$ EDTA could enhance the solubility of iron and calcium ions, leading to increase their availability for microalgae, which promote the lipid accumulation. Compared with the control, the total lipid content and lipid productivity increased by 28.2 and $29.7 \%$, respectively (Ren et al., 2014).

\section{Carbon sources}

\subsection{Inorganic carbon $\left(\mathrm{CO}_{2}\right)$}

Phototrophic cultivation is the most commonly used cultivation condition for microalgae lipid production probably due to it simple use and its advantage of the consumption of $\mathrm{CO}_{2}$ as carbon source for both cell growth and oil production. The Table 3 presents some examples of carbon on lipid production in microalgae.

Chlorella vulgaris has produced maximum biomass, lipid yield and lipid productivity at $8 \% \mathrm{CO}_{2}$. Most of its fatty acid were saturated fatty acid, $45 \%$ of the total lipid content was composed of unsaturated fatty acids, including $80 \%$ of high added-value essential fatty acids belonging to the $\omega 3$ and $\omega 6$ which have a great importance for human health (Ortiz Montoya et al., 2014). Similar results were obtained on C. vulgaris MSU AGM14 cultivated at $8 \% \mathrm{CO}_{2}$, with lipid content and lipid productivity equals to $18.6 \%$ and $11.89 \mathrm{mg}$. $\mathrm{L}^{-1} \cdot \mathrm{d}^{-1}$, respectively (Lakshmikandan et al., 2020).

The same microalgal specie cultured under a relatively high $\mathrm{CO}_{2}$ concentration $(10 \%)$ has given a similar lipid productivity equal of $6.9 \mathrm{mg} . \mathrm{L}^{-1} . \mathrm{d}^{-1}$ for 14 days of culture. Similar productivity was obtained from Botryococcus braunii. (5.51 mg.L $\left.\mathrm{L}^{-1} . \mathrm{d}^{-1}\right)$ with oleic acid as main component of the fatty acids content $(55 \%)$. At the opposite, the lipid 
Table 4. Examples of the impact of light on lipid production in some microalgae.

\begin{tabular}{|c|c|c|c|c|}
\hline Microalgae & Stress conditions & $\begin{array}{l}\text { Lipid content, } \\
\text { lipid productivity }\end{array}$ & Major lipids & References \\
\hline $\begin{array}{l}\text { Neochloris oleoabundans } \\
\text { HK-129 }\end{array}$ & $200 \mu \mathrm{mol}$ photons. $\mathrm{m}^{-2} \cdot \mathrm{s}^{-1}$ & $\begin{array}{l}24.4 \% \\
49.94 \mathrm{mg} . \mathrm{L}^{-1} \cdot \mathrm{d}^{-1}\end{array}$ & $\begin{array}{l}\text { oletic acid }(\mathrm{C} 18: 1), \text { palmitic acid } \\
(\mathrm{C} 16: 0) \text {, linolenic }(\mathrm{C} 18: 2)\end{array}$ & Sun et al. (2014) \\
\hline Scenedesmus abundans & $6000 \operatorname{lux}$ & $\begin{array}{l}32.8 \% \\
39.16 \mathrm{mg} \cdot \mathrm{L}^{-1} \cdot \mathrm{d}^{-1}\end{array}$ & $\begin{array}{l}\text { palmitic acid (C16:0), oletic acid } \\
(\mathrm{C} 18: 1)\end{array}$ & Mandotra et al. (2016) \\
\hline Nannochloropsis sp. & $700 \mu \mathrm{mol}$ photons. $\mathrm{m}^{-2} \cdot \mathrm{s}^{-1}$ & $\begin{array}{l}47 \% \\
410 \mathrm{mg} . \mathrm{L}^{-1} \cdot \mathrm{d}^{-1}\end{array}$ & $\begin{array}{l}\text { palmitic acid }(\mathrm{C} 16: 0) \text {, palmitoleic } \\
\text { acid }(\mathrm{C} 16: 1) \text {, eicosapentaenoic acid } \\
(\mathrm{C} 20: 5 n 3)\end{array}$ & Pal et al. (2011) \\
\hline Nannochloropsis oculata & $\begin{array}{l}\text { Blue LED follow by green } \\
\text { LED }\end{array}$ & $56.0 \%$, n.d & $\begin{array}{l}\text { palmitic acid (C16:0), oleic acid } \\
(\mathrm{C} 18: 1)\end{array}$ & Ra et al. (2016) \\
\hline Nannochloropsis salina & $\begin{array}{l}\text { Blue LED follow by green } \\
\text { LED }\end{array}$ & $52.0 \%$, n.d & $\begin{array}{l}\text { palmitic acid (C16:0), oleic acid } \\
(\mathrm{C} 18: 1)\end{array}$ & \\
\hline Nannochloropsis oceanica & $\begin{array}{l}\text { Blue LED follow by green } \\
\text { LED }\end{array}$ & $53.0 \%$, n.d & $\begin{array}{l}\text { palmitic acid (C16:0), oleic acid } \\
(\mathrm{C} 18: 1)\end{array}$ & \\
\hline
\end{tabular}

n.d: not determined

productivity of Scenedesmus sp. was $20.65 \mathrm{mg} \cdot \mathrm{L}^{-1} \cdot \mathrm{d}^{-1}$ (Yoo et al., 2010).

Opposite results were obtained by Lv et al. (2010). Indeed, higher lipid contents in Chlorella vulgaris were found with different $\mathrm{CO}_{2}$ concentration ranged 0.5 to $12 \%$. Cultures bubbled with $0.5,1.0,6.0$ and $12.0 \% \mathrm{CO}_{2}$ have given the following lipid content of 18.1, 20.0, 16.3 and $14.2 \%$, respectively. Furthermore, it seems that lower $\mathrm{CO}_{2}$ concentration favored the lipid accumulation because of a higher lipid productivity at $1.0 \% \mathrm{CO}_{2}$, which is 2.6 times higher than $12.0 \% \mathrm{CO}_{2}$.

Finally, no significant difference was found in the proportion of lipid classes between $2 \% \mathrm{CO}_{2}$ and air culture conditions in Chlorella vulgaris, but alterations in the composition of the fatty acids were observed. The relative content of $\mathrm{C} 18: 2$ was higher in $2 \% \mathrm{CO}_{2}$, while that of $\mathrm{C} 18: 3$ was much lower than in air, inducing an increase of C18:2/ C18:3 ratio of 3.9 fold (Tsuzuki et al., 1990).

\subsection{Organic carbon}

Some microalgae and Cyanobacteria are also able, in addition to atmospheric $\mathrm{CO}_{2}$ to use carbohydrates or simple organic acids such as glucose, glycerol or acetate. The main advantage of heterotrophic culture is that it makes it possible to produce biomass and molecules of interest with a much greater yield compared to autotrophic culture, in some cases reducing production costs. For example, the amount of floridean starch in Galdieria sulphuraria increases significantly when it is cultivated in the presence of glucose, whether in heterotrophic or mixotrophic mode (concomitant presence of at least one organic carbonaceous substrate and light). In addition, its lipid content, and more particularly in polyunsaturated fatty acids (PUFA), was greater in heterotrophic conditions (Sakurai et al., 2016). Other examples are presented Table 3.

Lipids obtained from Chlorella species in heterotrophic cultivation are considered as a suitable feedstock for biodiesel production. The growth and lipid productivity of an isolated microalga Chlorella vulgaris ESP-31 were investigated under different media and cultivation conditions, including phototrophic growth, heterotrophic growth, photoheterotrophic growth and mixotrophic growth by Yeh and Chang (2012). They found that mixotrophic cultivation, with all the culture media tested, has given both the higher lipid content and lipid productivity.

Wang et al. (2012a) have conducted a mixotrophic cultivation of Phaeodactylum tricornutum with different organic carbon sources (sodium acetate, soluble starch and glucose) at different concentrations (from 0.5 to 5.0 g. $\mathrm{L}^{-1}$ ). Results showed that the lipid content and lipid productivity of the microalga tending to increase significantly in all tested mixotrophic conditions, especially with glucose. The maximum lipid productivities in mixotrophic cultures with glucose, starch and acetate in medium were respectively 4.6-, 2.0-, and 1.7-fold of those obtained in the control. Total fatty acids were mainly composed of $\mathrm{C} 16: 1$ (palmitoleic acid), C16:0 (hexadecylic acid) and $\mathrm{C} 20: 5 \mathrm{n} 3$ (eicosapentaenoic acid, EPA) for all conditions (Wang et al., 2012a). At the opposite, no significant differences in biomass or lipid production were observed in mixotrophic cultivation with acetate in Scenedesmus abundans (Gupta and Pawar, 2018).

Crude glycerol is a major by-product accumulated during the production of biodiesel which have usually has little commercial value. Nevertheless, its glut represents option for the valueadded conversion. One possibility for its utilization is to use it as a substrate for fermentation, as example in the oleaginous microalga Schizochytrium limacinum which can produce significant amounts of total lipids and specially docosahexaenoic acid (DHA, 22:6n-3) (Chi et al., 2007; Pyle et al., 2008).

For example, mixotrophic conditions with crude glycerol improved both the growth and the accumulation of triacylglycerols (TAG) in Chlorella vulgaris, Botryococcus braunii and Scenedesmus sp. (Choi and Yu, 2015). The three microalgal species had between 2 and 13\% higher lipid content compare to the autotrophic condition. The highest TAG content was obtained for all strains with 5 g.L $\mathrm{L}^{-1}$ glycerol 
Table 5. Examples of the impact of temperature on lipid production in some microalgae.

\begin{tabular}{|c|c|c|c|c|}
\hline Microalgae & Stress conditions & $\begin{array}{l}\text { Lipid content, } \\
\text { lipid productivity }\end{array}$ & Major lipids & References \\
\hline $\begin{array}{l}\text { Scenedesmus sp. } \\
\text { LX1 }\end{array}$ & $20^{\circ} \mathrm{C}$ & $\begin{array}{l}35.0 \% \\
112.0 \mathrm{mg} . \mathrm{L}^{-1} . \mathrm{d}^{-1}\end{array}$ & $\begin{array}{l}\mathrm{C} 22: 3 \mathrm{n} 8) \text {, linoleic acid }(\mathrm{C} 18: 2 \mathrm{n} 7) \\
\text { palmitic acid }(\mathrm{C} 16: 0)\end{array}$ & Xin et al. (2011) \\
\hline $\begin{array}{l}\text { Chlorella minutissima } \\
\text { UTEX } 2341\end{array}$ & $20^{\circ} \mathrm{C}$ & $15.0 \%$, n.d & $\begin{array}{l}\text { linoleic acid (C18:2n6), oleic acid } \\
\text { (C18:1n9), palmitic acid (C16:0) }\end{array}$ & Cao et al. (2014) \\
\hline $\begin{array}{l}\text { Chlamydomonas reinhardtii } \\
\text { BAF-J5 }\end{array}$ & $32^{\circ} \mathrm{C}$ & $76.4 \%$, n.d & $\begin{array}{l}\text { palmitic acid }(\mathrm{C} 16: 0) \text {, oleic acid } \\
(\mathrm{C} 18: 1) \text {, linolenic }(\mathrm{C} 18: 2)\end{array}$ & James et al. (2013) \\
\hline
\end{tabular}

(15.91, 16.24 and $16.41 \%$ for Chlorella vulgaris, Scenedesmus sp. and Botryococcus braunii, respectively).

\section{Light}

One of the most essential parameter to the production of algal biomass is the light source. The photosynthesis process is closely linked to the quantity of photons perceived by the cell. A decrease in Photosynthetic Photon Flux Density (PPFD) leads to suppression of $\mathrm{CO}_{2}$ concentrating mechanism (CCM) and a decrease in $\mathrm{CO}_{2}$ transport capacity in Anabaena variabilis and Chlamydomonas reinhardtii (Spalding et al., 1984; Ogawa and Ogren, 1985). To optimize the use of photons, it is necessary to study the influence of light intensity on the process of photosynthesis for each strain. For this it is necessary to determine the growth rates as a function of the PPFD. A study was carried out in Chlamydomonas reinhardtii and allows to divide the growth curve into three parts: (1) the first has shown a linear relationship between the incident photon flux and the growth rate, proving that light is a limiting factor for growth; (2) the second corresponds to the light intensities that cause saturation of the photosynthetic process, corresponding to an optimal light intensity meaning all photons were used; (3) Finally, the third corresponds to the higher light intensities which lead to a decrease in photosynthetic activity and therefore have a negative impact on growth. This is photoinhibition (Janssen et al., 2000). From this point of view, use an adequate light intensity favors both overproduction of biomass and microalgal lipids (Khotimchenko and Yakovleva, 2005; Solovchenko et al., 2008; Gim et al., 2016) (Tab. 4).

Sun et al. (2014) have observed a correlation between TAG content in Neochloris oleoabundans HK-129 and the increase of light intensity. The maximum TAG content and productivity were obtained at $200 \mu \mathrm{mol}$ photons. $\mathrm{m}^{-2} \cdot \mathrm{s}^{-1}$. C16/C18 fatty acids $(90.02 \%)$, saturated fatty acids $(29.82 \%)$ and monounsaturated fatty acids $(32.67 \%)$ were the major constituents of its lipid composition, which is suitable for biodiesel synthesis. In addition, high irradiances stimulated a decrease of chlorophyll a, fucoxanthin and amino acids content and induce the conversion of polar fatty acids to saturated and unsaturated fatty acid in Isochrysis galbana (Aguilera-Sáez et al., 2019).

Time exposure to the light could also affect the fatty acid composition. In Chlorella vulgaris the maximum of total saturated fatty acid was recorded at $100 \mu \mathrm{mol}$ photons. $\mathrm{m}^{-2} \cdot \mathrm{s}^{-1}$ with a $16 \mathrm{~h}: 8 \mathrm{~h}$ photoperiod. At the opposite, monounsaturated and polyunsaturated fatty acids decreased with increasing irradiance and light duration. The maximum of total MUFA $(15.93 \%)$ and PUFA $(27.40 \%)$ was recorded at $37.5 \mu \mathrm{mol}$ photons. $\mathrm{m}^{-2} \cdot \mathrm{s}^{-1}$ with a $8 \mathrm{~h}: 16 \mathrm{~h}$ photoperiod (Amini Khoeyi et al., 2012).

Nzayisenga et al. (2020) have shown that increased light intensity from 50 to $300 \mu \mathrm{mol}$ photons. $\mathrm{m}^{-2} \cdot \mathrm{s}^{-1}$ induced changes in lipid composition in Desmodesmus sp., Scenedesmus obliquus and Chlorella vulgaris with lower amounts of C18:3, and higher contents of C18:1 which became the most abundant fatty acid. This increase in intracellular lipid when microalgae are subjected to high light intensity could be attributed to the oxidative stress from photocatalyst. Under high light stress, microalgae accumulate a large amount of reactive oxygen species (ROS) including singlet oxygen $\left(\mathrm{O}_{2}\right)$, superoxide $\left(\mathrm{O}_{2}{ }^{-}\right)$, hydrogen peroxide $\left(\mathrm{H}_{2} \mathrm{O}_{2}\right)$, and hydroxyl radicals, resulting in the direct decomposition of the lipids, protein, and nucleic acids. In 2014, Kang et al. (2014) have exposed Chlorella vulgaris UTEX 265 to an artificial oxidative stress using various concentrations of $\mathrm{TiO}_{2}$ ranging from 0.1 to $5 \mathrm{~g} . \mathrm{L}^{-1}$ under UV-A illumination. FAME composition of C18:3 fatty acid (linolenic acid) was highest with $0.1 \mathrm{~g} . \mathrm{L}^{-1}$ of $\mathrm{TiO}_{2}$ under 4 days induction time, and slightly decreased, with increased concentration of $\mathrm{TiO}_{2}$. Furthermore, $0.1 \mathrm{~g} . \mathrm{L}^{-1}$ of $\mathrm{TiO}_{2}$ given the best lipid content and lipid productivity in the 2 days induction condition $\left(11.35 \%\right.$ and $18.16 \mathrm{~m} . \mathrm{L}^{-1} \cdot \mathrm{d}^{-1}$, respectively). The same year, Yilancioglu et al. (2014) have submitted the microalgae Dunaliella salina Tuz_KS_01 to an oxidative stress with different concentrations of $\mathrm{H}_{2} \mathrm{O}_{2}$. The ROS accumulation and lipid contents increased with increasing $\mathrm{H}_{2} \mathrm{O}_{2}$ concentrations, leading to lipid accumulation up to $44 \%$.

The wavelength of light is just as important as its intensity. Different wavelength will produce different results in both biomass production and lipid content. For example, Nannochloropsis salina, Nannochloropsis oceanica and Nannochloropsis oculata growth faster under blue light-emitting diode (LED) and have the highest lipid content under green LED. A two-phase culture was then tested, with blue LED in phase 1 to optimize growth follow by green LED to upgrade the amount of lipid. The lipid contents of the three Nannochloropsis sp. reached 52, 53 and 56\% for N. salina, $N$. oceanica and N. oculata, respectively (Ra et al., 2016). In Scenedesmus obliquus, both blue and red LEDs given the best biomass productivity and lipid content compare to the white light. Furthermore, a combined blue-red illumination with 1:1 ratio has given better results compare to only one wavelength use (Abomohra et al., 2019). 
Table 6. Examples of impact of salt on lipid production by microalgae.

\begin{tabular}{|c|c|c|c|c|}
\hline Microalgae & Stress conditions & $\begin{array}{l}\text { Lipid content, } \\
\text { lipid productivity }\end{array}$ & Major lipids & References \\
\hline $\begin{array}{l}\text { Dunaliella tertiolecta } \\
\text { ATCC } 30929\end{array}$ & $\mathrm{NaCl}$ & $67.8 \%$, n.d & n.d & Takagi et al. (2006) \\
\hline $\begin{array}{l}\text { green microalga } \\
\text { UTEX 2219-4 }\end{array}$ & $\mathrm{NaCl}$ & $30.1 \%$, n.d & n.d & Wang et al. (2011) \\
\hline $\begin{array}{l}\text { green microalga } \\
\text { UTEX 2219-4 }\end{array}$ & $\mathrm{KCl}$ & $27.6 \%$, n.d & n.d & \\
\hline $\begin{array}{l}\text { Monoraphidium dybowski } \\
\text { LB50 }\end{array}$ & $i \mathrm{NaCl}$ & $\begin{array}{l}41.7 \% \\
57.50 \mathrm{mg} . \mathrm{L}^{-1} \cdot \mathrm{d}^{-1}\end{array}$ & n.d & Yang et al. (2014) \\
\hline Scenedesmus obliquus & $\mathrm{NaCl}$ & $36.0 \%$, n.d & $\begin{array}{l}\text { palmitic acid (C16:0), oleic acid } \\
(\mathrm{C} 18: \ln 9 \mathrm{c})\end{array}$ & Kaewkannetra et al. (2012) \\
\hline $\begin{array}{l}\text { Chlorella minutissima } \\
\text { UTEX } 2341\end{array}$ & $\mathrm{NaCl}$ & $31.8 \%$, n.d & $\begin{array}{l}\text { linoleic acid (C18:2n6), oleic acid } \\
\text { (C18:1n9), palmitic acid (C16:0) }\end{array}$ & Cao et al. (2014) \\
\hline
\end{tabular}

n.d: not determined

\section{Temperature}

Among the various culture conditions, enhancement of lipid production in microalgae by temperature is studied long ago (Norman and Thompson, 1985). The effect of temperature on microalgal growth and lipid production is similar to that of light intensity. Actually, microalgal growth as well as lipid production exponentially increases to a certain extent as the temperature increases and reaches an optimal level, dependent on each microalga strain, as presented in Table 5 .

As an example, Jiang and Gao (2004) have showed that the production of EPA and PUFA by Phaeodactylum tricornutum increased by 50 and $20 \%$, respectively, when the temperature switch from 25 to $20^{\circ} \mathrm{C}$ after 6 days of culture, respectively. In Nannochloropsis salina, both TFA and EPA contents increased under a low culture temperature $\left(17^{\circ} \mathrm{C}\right)$ compared to moderate temperatures of 21 and $26^{\circ} \mathrm{C}$ (Hoffmann et al., 2010).

James et al. (2013) have compared lipid production at different temperatures, in both quantity and quality, between two strains of Chlamydomonas reinhardtii: a wild type and its starchless mutant BAF-J5. There was significant increased in total fatty acid content for all temperature in the mutant compare to wild type. Furthermore, shifting temperature from 25 to $32^{\circ} \mathrm{C}$ resulted of maximum quantity of fatty acid in BAF-J5, which is 6.15 fold higher than wild type. Shifting temperature to $17^{\circ} \mathrm{C}$, reduced both the total amount of fatty acid from 68.29 to $55.63 \%$ DW and proportions of unsaturated fatty acid, especially C18:1.

Finally, Wei et al. (2015) studied temperature effects on lipid properties of microalgae Tetraselmis subcordiformis and Nannochloropsis oculata. They found that increased temperature led to a decrease in neutral lipid and polyunsaturated fatty acids (PUFA) while saturated fatty acids increased (SFA). In Tetraselmis subcordiformis these changes were accompanied by an increased in monounsaturated fatty acids (MUFA), whereas it was decreased for Nannochloropsis oculata. These studies demonstrate how a critical environmental factor, such as temperature, can modulate both the amount and composition of fatty acids and it is important for costly refining of biofuels.

\section{Salinity}

Dunaliella species provide the best examples of microalgae that can tolerate high salt concentrations. The ability of Dunaliella species to proliferate over practically the saturation range of salinities makes them good candidates to study salinity effects on lipid production in microalgae. As an example, increase $\mathrm{NaCl}$ concentration from 0.5 to $1.0 \mathrm{M}$ resulted in $11 \%$ of more intracellular lipid content and $39 \%$ of the proportion of triacylglyceride (TG) in Dunaliella tertiolecta ATCC 30929. Also, addition of 0.5 or $1.0 \mathrm{M} \mathrm{NaCl}$ at mid or the end of log phase during cultivation, with initial $\mathrm{NaCl}$ concentration of $1.0 \mathrm{M}$ gave a significant increase in lipid content $(70 \%)$. However no significant change in TG fraction was observed (Takagi et al., 2006). Increased $\mathrm{NaCl}$ concentrations from 13 to 40 g. $\mathrm{L}^{-1}$ enhanced TFA content in Nannochloropsis sp. EPA production was slightly higher at the lowest level of salinity (Pal et al., 2011).

The effect of salinity on lipid storage was also considered in Scenedesmus obliquus, using $\mathrm{NaCl}$ solutions of varying concentrations $(0.05,0.2$, and $0.3 \mathrm{M})$. Algal oil storage of up to $36 \%$ DW was observed in the culture supplemented with $0.3 \mathrm{M} \mathrm{NaCl}$ at day 15 after salt stress, which was 3.8 fold higher than before the salt stress induction (Kaewkannetra et al., 2012).

In the diatom Nitzschia laevis Hust, the maximum specific growth rate and biomass concentration were obtained at $10 \mathrm{~g}$. $\mathrm{L}^{-1} \mathrm{NaCl}$. Increase salinity induces a diminution of neutral lipids (NL) from 78.6 to $43.4 \%$ of total lipids, especially TAG. On the contrary, the content of phospholipids (PL) increased from 11.6 to $39.9 \%$ of total lipids. EPA represents the major PUFA and its highest content was obtained at 20 g.L ${ }^{-1} \mathrm{NaCl}$ (Chen et al., 2008).

In order to avoid inhibited cells growth promote by $\mathrm{NaCl}$ stress, Duan et al. (2012) decided to applied multiple osmotic stress with different $\mathrm{NaCl}$ additions to Chlorella vulgaris to improved lipid production. After $180 \mathrm{~h}$, three induction of $\mathrm{NaCl}$ stress $\left(2\right.$ g.L $\mathrm{L}^{-1}$ at $80 \mathrm{~h}, 4 \mathrm{~g} . \mathrm{L}^{-1}$ at $100 \mathrm{~h}$ and 6 g.L $\mathrm{L}^{-1}$ at $120 \mathrm{~h}$ ) achieved a lipid yield of $3.16 \mathrm{~g} . \mathrm{L}^{-1}$ and corresponding to $58.6 \%$ of intracellular lipid content, which were 21 and 
Table 7. Examples of the impact of hormones on lipid production by microalgae.

\begin{tabular}{|c|c|c|c|c|}
\hline Microalgae & Stress conditions & $\begin{array}{l}\text { Lipid content, } \\
\text { lipid productivity }\end{array}$ & Major lipids & References \\
\hline $\begin{array}{l}\text { Scenedesmus quadricauda } \\
\text { SDEC-13 }\end{array}$ & $\begin{array}{l}\text { Diethyl aminoethyl } \\
\text { hexanoate }\end{array}$ & $\begin{array}{l}28.4 \% \\
32.69 \mathrm{mg} \cdot \mathrm{L}^{-1} \cdot \mathrm{d}^{-1}\end{array}$ & $\begin{array}{l}\text { palmitic acid }(\mathrm{C} 16: 0) \text {, oleic acid } \\
(\mathrm{C} 18: 1) \text {, linolenic }(\mathrm{C} 18: 2)\end{array}$ & Jiang et al. (2015) \\
\hline $\begin{array}{l}\text { Chlorella ellipsoidea } \\
\text { SDEC-11 }\end{array}$ & $\begin{array}{l}\text { Diethyl aminoethyl } \\
\text { hexanoate }\end{array}$ & $\begin{array}{l}32.5 \% \\
39.13 \mathrm{mg} . \mathrm{L}^{-1} \cdot \mathrm{d}^{-1}\end{array}$ & $\begin{array}{l}\text { palmitic acid }(\mathrm{C} 16: 0), \text { linolenic } \\
(\mathrm{C} 18: 2) \text {, oleic acid }(\mathrm{C} 18: 1)\end{array}$ & \\
\hline $\begin{array}{l}\text { Scenedesmus obliquus } \\
\text { GU732418 }\end{array}$ & $\begin{array}{l}\text { Indole-3-acetic acid and } \\
\text { diethyl aminoethyl } \\
\text { hexanoate }\end{array}$ & n.d & $\begin{array}{l}\text { g-linolenic acid (C18:3n6), } \\
\text { palmitic acid (C16:0) }\end{array}$ & Salama et al. (2017) \\
\hline $\begin{array}{l}\text { Ourococcus multisporus } \\
\text { GU732424 }\end{array}$ & $\begin{array}{l}\text { Indole-3-acetic acid and } \\
\text { diethyl aminoethyl } \\
\text { hexanoate }\end{array}$ & n.d & $\begin{array}{l}\gamma \text {-linolenic acid }(\mathrm{C} 18: 3 \mathrm{n} 6), \\
\text { palmitic acid }(\mathrm{C} 16: 0), \text { linoleic acid } \\
(\mathrm{C} 18: 2 \mathrm{n} 6 \mathrm{c})\end{array}$ & \\
\hline $\begin{array}{l}\text { Chlorella vulgaris } \\
\text { FR751187 }\end{array}$ & $\begin{array}{l}\text { Indole-3-acetic acid and } \\
\text { diethyl aminoethyl } \\
\text { hexanoate }\end{array}$ & n.d & $\begin{array}{l}\gamma \text {-linolenic acid }(\mathrm{C} 18: 3 \mathrm{n} 6) \\
\text { palmitic acid }(\mathrm{C} 16: 0), \text { oleic acid } \\
(\mathrm{C} 18: \ln 9 \mathrm{c})\end{array}$ & \\
\hline $\begin{array}{l}\text { Monoraphidium sp. } \\
\text { QLY-1 }\end{array}$ & Strigolactone & $\begin{array}{l}48.8 \% \\
63.7 \mathrm{mg} . \mathrm{L}^{-1} . \mathrm{d}^{-1}\end{array}$ & n.d & Song et al. (2019) \\
\hline $\begin{array}{l}\text { Nannochloropsis oceanica } \\
\text { CASA CC201 }\end{array}$ & Methyl jasmonate & n.d & $\begin{array}{l}\text { palmitic acid (C16:0), palmitoleic } \\
\text { acid }(\mathrm{C} 16: 1) \text {, oleic acid (C18:1) }\end{array}$ & Udayan et al. (2020) \\
\hline $\begin{array}{l}\text { Tetradesmus obliquus } \\
\text { BPL16 }\end{array}$ & Salicylic acid & $\begin{array}{l}30.1 \% \\
326 \mathrm{mg} . \mathrm{L}^{-1} \cdot \mathrm{d}^{-1}\end{array}$ & n.d & Esakkimuthu et al. (2020) \\
\hline $\begin{array}{l}\text { Tetradesmus obliquus } \\
\text { BPL16 }\end{array}$ & Jasmonic acid & $\begin{array}{l}27.5 \% \\
357 \mathrm{mg} . \mathrm{L}^{-1} \cdot \mathrm{d}^{-1}\end{array}$ & $\begin{array}{l}\text { oleic acid (C18:1), palmitic acid } \\
(\mathrm{C} 16: 0)\end{array}$ & \\
\hline $\begin{array}{l}\text { Tetradesmus obliquus } \\
\text { BPL16 }\end{array}$ & $p$-coumaric acid & $\begin{array}{l}30.7 \% \\
341 \mathrm{mg} \cdot \mathrm{L}^{-1} \cdot \mathrm{d}^{-1}\end{array}$ & $\begin{array}{l}\text { oleic acid (C18:1), palmitic acid } \\
(\mathrm{C} 16: 0), \mathrm{C} 16: 2\end{array}$ & \\
\hline
\end{tabular}

n.d: not determined

$22.8 \%$ higher than control. Another addition of 6 g. $\mathrm{L}^{-1}$ at $140 \mathrm{~h}$ did not upgrade both lipid content and lipid yield. These result suggested that application of multiple osmotic stress could be a promising method to lipid overproduction while decreasing the loss of biomass. Other examples are presented in Table 6 .

\section{Hormones}

The approaches presented in the previous parts have been known and studied for many years, on various microalgae and Cyanobacteria. Recently, the literature has seen a growing number of publications about the use of hormones to improve lipid production in microalgae (Tab. 7).

Many types of hormones have been used more or less successfully. Among the most promising ones, Jiang et al. (2015) have shown that very low concentration of DA-6 $\left(10^{-7} \mathrm{M}\right)$ could enlarge cell size and enhance cell growth of Scenedesmus quadricauda SDEC-13 and Chlorella ellipsoidea SDEC-11. Biomass productivity was 14 and 336\% higher than without DA-6, respectively. The higher lipid productivity occurred in $10^{-7} \mathrm{M}$ medium, representing $30 \%$ and $15 \%$ of increase compare of controls (Jiang et al., 2015).

In 2017, Salama et al. (2017) found that indole-3-acetic acid (IAA, auxin) and diethyl aminoethyl hexanoate (DA-6) positively affect the growth and lipid productivity of Scenedesmus obliquus GU732418, Ourococcus multisporus GU732424 and Chlorella vulgaris FR751187. The amounts of PUFA were significantly increased.

In Desmodesmus sp. JS07, supplementation of culture medium with $10 \mathrm{mg} . \mathrm{L}^{-1}$ of indole-3-butyric acid (IBA) and indole-3-propionic acid (IPA) significantly increase the lipid content and lipid yield. Higher lipid content was observed with $10 \mathrm{mg}^{-\mathrm{L}^{-1}}$ benzylaminopurine (BAP) treatments. More, a combination of IBA $\left(10 \mathrm{mg} . \mathrm{L}^{-1}\right)$ and BAP $\left(5 \mathrm{mg} . \mathrm{L}^{-1}\right)$ resulted to better biomass concentration and lipid content, sign of synergistic effect of auxin and cytokinins (Singh et al., 2020).

Another hormone, the strigolactone was used on Monoraphidium $\mathrm{sp}$. QLY-1 cultures and led to enhance lipid content and lipid productivity under $1 \mu \mathrm{M}$ induction compared (Song et al., 2019). Nevertheless, higher lipid content and lipid productivity were obtained in nitrogen deficiently without strigolactone induction (Song et al., 2020). Similar study performed on Nannochloropsis oceanica CASA CC201 have shown that treatment with $10 \mathrm{ppm}$ of methyl jasmonate (MeJA) also promoted biomass and lipid yields, with an increase of $22 \%$ and $49 \%$ more than control (Udayan et al., 2020). Increase MeJA concentration beyond $10 \mathrm{ppm}$ induce a decrease of essential $\omega 3$ fatty acid but promoted monounsaturated fatty acid production, especially oleic acid. 
Table 8. Examples of the impact of co-cultivation with microorganisms on lipid production by microalgae.

\begin{tabular}{|c|c|c|c|c|}
\hline Microalgae & $\begin{array}{l}\text { Co-cultivated } \\
\text { microorganisms }\end{array}$ & $\begin{array}{l}\text { Lipid content, } \\
\text { lipid productivity }\end{array}$ & Major lipids & References \\
\hline $\begin{array}{l}\text { Tetraselmis striata } \\
\text { KCTC1432BP }\end{array}$ & $\begin{array}{l}\text { Pelagibaca bermudensis } \\
\text { KCTC 13073BP }\end{array}$ & n.d & $\begin{array}{l}\text { palmitic acid (C16:0), } \\
\text { linolenic acid (C18:2), } \\
\text { stearic acid (C18:0) }\end{array}$ & Park et al. (2017) \\
\hline Tetraselmis striata & Stappia $\mathrm{sp}$. & n.d & palmitic acid (C16:0), & \\
\hline КСТC1432BP & КCTC 13072BP & & $\begin{array}{l}\text { linolenic acid (C18:2), } \\
\text { stearic acid (C18:0) }\end{array}$ & \\
\hline Chlorella vulgaris & $\begin{array}{l}\text { Mesorhizobium sangaii } \\
13218\end{array}$ & $\begin{array}{l}51.2 \% \\
96.8 \mathrm{mg} . \mathrm{L}^{-1} . \mathrm{d}^{-1}\end{array}$ & $\begin{array}{l}\text { oleic acid (C18:1), } \\
\text { palmitic acid (C16:0), } \\
\text { linolenic acid (C18:2) }\end{array}$ & Wei et al. (2020) \\
\hline $\begin{array}{l}\text { Chlorella sacchrarophila } \\
\text { FACHB } 4\end{array}$ & $\begin{array}{l}\text { Cellvibrio pealriver } \\
\text { PR1 }\end{array}$ & $\begin{array}{l}53.9 \% \\
61.9 \mathrm{mg} . \mathrm{L}^{-1} \cdot \mathrm{d}^{-1}\end{array}$ & n.d & Xie et al. (2021) \\
\hline Chlorella protothecoides & Aspergillus fumigatus & n.d & $\begin{array}{l}\text { linolenic acid (C18:2), } \\
\text { palmitic acid (C16:0) }\end{array}$ & Chu et al. (2021) \\
\hline
\end{tabular}

n.d: not determined

Another interesting approach is to use the $p$-coumaric acid as a suggested novel growth regulator typically found in wastewaters of agricultural origin. $1 \mathrm{mM}$ increased the lipid accumulation up to $30.7 \%$, leading to a higher lipid production in Tetradesmus obliquus BPL16. Furthermore, neutral lipids were enhanced under $10 \mathrm{mM}$ of jasmonic acid and $1 \mathrm{mM}$ of $p$-coumaric acid to the detriment of both phospholipids and glycolipids. The SFA content decreased of $37-40 \%$ and the MUFA content increased of $36-56 \%$. Oleic acid was the major constituent, but its proportion was drastic increase up to 81.7 and $73.6 \%$ of TFA, respectively (Esakkimuthu et al., 2020).

\section{Co-cultivation with microorganisms}

Diverse strategies can be used to get a biologically plausible optimization of the microalgae culture such as using indigenous microalgae added with other microorganisms such as fungi or bacteria. In nature or industrial processes as wastewater treatment plant, microalgae co-exist with many other microorganisms in complex microbial communities which may have influence on microalga growth and lipid production (Cho et al., 2015). These positive effects can be explained by interactions between the microorganisms and microalgae called symbiosis. The oxygen produced by the microalgae along the photosynthetic process can be used by the microorganisms, which produced in response carbon dioxide for microalgae. Additionally, there is no competition for the carbon source since microalgae and microorganisms consume inorganic and organic carbon, respectively. This fact results in an enhanced yield of biomass and higher concentrations of secondary metabolites (carbohydrates, proteins, and lipids) (Tab. 8).

The impact of two isolated bacteria (P. bermudensis and Stappia sp.) have been studied on T. striata growth and lipid content. The results showed that P. bermudensis and Stappia $\mathrm{sp}$. have stimulated the increased of cell density of T. striata on the 25 th day compared to the axenic T. striata culture. The analyses of lipid content in the treated and axenic cultures suggested that the axenic cultures had better capacity to accumulate lipids. However, total lipid productivity was still substantially promoted by the bacterial treatment compare to control because of the increase of total biomass production (Park et al., 2017).

Mixotrophic cultivation also significantly affected total fatty acid composition in C.minutissima. Compared to axenic C. minutissima, provision of organic substrate had a positive effect on both fatty acid and neutral lipid content in co-cultures of $C$. minutissima and $E$. coli. This was particularly true at $10 \mathrm{~g}$. $\mathrm{L}^{-1}$ glucose where total fatty acid and total lipid contents increased to $40 \%$ and $32 \%$, respectively. Compared to axenic culture, co-culture with 10 g.L $\mathrm{L}^{-1}$ glycerol substrate leading to a large increase in oleic acid and linolenic acid contents. This resulted of a decrease of C18:3 and C16:0 content (Higgins and VanderGheynst, 2014). A later study revealed that a positive effect may be traced to E.coli's provision of thiamine derivatives and degradation products to A.protothecoides (Higgins et al., 2016).

In 2020, Wei et al. (2020) have co-cultivated Chlorella vulgaris with Mesorhizobium sangaii under nitrogen deficiency condition. The maximum biomass, lipid content and productivity of algae in the co-cultures were $1.5,2.2$, and 3.3 times higher than those of the pure algae culture. Furthermore, the neutral lipid productivity was 3.5-fold higher compared to control, resulting in an increase of $50 \%$ of neutral lipid proportion. FAME profile was also affected. The proportion of PUFA and MUFA were increased whereas the proportion of SFA was decreased. In addition the content of C18:1 and C18:2 were also significantly increased thanks to the consortium system (Wei et al., 2020). 
More recently, a continuous two-step (CTS) cultivation strategy based on separated co-culturing was developed. At the first-step co-cultivation, Chlorella sacchrarophila was grown in bioreactor while Cellvibrio pealriver was grown in a dialysis bag as inner bag inside the bioreactor. Then, the inner bag was removed which then start the second-step cultivation of C. sacchrarophila. Results shown that after 3 days of cocultivation, the production of microalgal biomass was similar with that obtained in single reactor. The microalgal growth almost ceased after that the inner bag being removed. The maximum biomass production was determined as $1725.41 \mathrm{mg}$. $\mathrm{L}^{-1}$ which was lower compared to microalga grown in onestep co-cultivation. At the opposite, the microalgal lipid content immediately increased after removing the inner bag and reached $53.89 \%$ after 15 days cultivation, which was almost 2.5-fold higher than the one-step co-cultivation. The microalgal lipid production in CTS and one-step co-cultivation were determined as 929.79 and $607.90 \mathrm{mg} . \mathrm{L}^{-1}$, respectively (Xie et al., 2021).

Chlorella vulgaris and Streptomyces rosealbus were cocultivated to evaluate the impact of co-culture system in microalgae growth and lipid production. The co-cultured microalgae produced $1.42 \mathrm{~g} . \mathrm{L}^{-1}$ of biomass and, which represented $33 \%$ higher biomass productivity compare to the control. The maximum lipid production and productivity were increased by $80 \%$. This result can be explained by the symbiosis between $C$. vulgaris and $S$. rosealbus that triggered Trp biosynthesis to increased volume. Trp is the main precursor for IAA secretion pathway. An augmentation of around $82-140 \%$ of IAA production was recorded in coculture system compared to monoculture, which lead to significant elevation of microalgal biomass and lipid productivity. The co-culture has shown no significant effect on the total FAMEs. However, the SFAs, MUFAs and PUFAs ratios showed significant variations compared to control, with an increase of $70 \%$ of PUFA and a decrease of $12 \%$ of MUFA (Lakshmikandan et al., 2021).

As microalgae/bacteria co-culture, co-culturing oleaginous yeast and microalgae have been studied extensively in the recent years for enhancing lipid productivity. In most of the cases, this strategy resulted in increasing the lipid productivity in both microalgae and yeast cultures.

Arora et al. (2019) have recently highlighted both the metabolic links between the lipid biosynthesis pathway of yeast and microalgae, and factors affecting the lipid productivity in the co-culturing system. According to them, the strain selection is the most important parameters. The best yeast and microalgal species to promote lipid production in coculture system belong the genera of Rhodotorula sp. and Chlorella sp. The second more important abiotic factor was the microalgae/yeast ratio. They determined that the optimal value was $1: 1$.

More recently, Chu et al. (2021) have compiled results of the biomass and lipid concentrations obtained from separately cultured fungus and algae or co-cultured pellets. Compared with mono-cultivation, the significant increase in biomass and lipid yields could be observed in co-cultured microalgal/ fungus co-culture, probably due to the symbiosis system. The maximum biomass and lipid yield were obtained using Aspergillus fumigatus co-cultivated with Chlorella protothecoides. It was 2 and 2.15 higher compared to the respective monocultures. However, the microalgal/fungus combination has no significant effect on the FAMEs profile, since it was mainly composed of the same lipids that the microalgal monoculture (C16:0 and C18:2) (Chu et al., 2021).

\section{Multi factor optimization}

\subsection{Experimental approach}

Each environmental parameter could be optimized independently each other in order to improve the lipid production in microalgae. However, the culture process is a complex system in which many parameters can interact with each other. It is therefore particularly advantageous to cooptimize these parameters by taking account of their interactions in order to improve the lipid productivity. Recent reports have presented the potential of combining abiotic stress factors to improve the lipid productivity in microalgae.

In 2016, Kwak et al. (2016) studied the combined effect of various stress conditions on lipid productivity in Chlamydomonas, Chorella, Scenedesmus and Neochloris strains. Compared to the only nitrogen starvation stress, its combined effect with high salt stress condition has improved the lipid productivities of Chlamydomonas species up to $50 \%$ and $30 \%$ for Chlorella protothecoides. The lipid productivities of C. vulgaris and N. oleoabundans were improved up to $39 \%$ and $37 \%$ respectively under the combined condition of $\mathrm{N}$-starvation and $30^{\circ} \mathrm{C}$ temperature compared to the maximum with single stress condition. In C. zofingiensis, the increase of lipid production up to $44 \%$ with the combined effects of $30^{\circ} \mathrm{C}$ culture temperature and high $\mathrm{NaCl}$ concentration. The optimal combined stress conditions in Scenedesmus sp. were high temperature and $10-\mathrm{pH}$. It induced 1.54-fold higher lipid productivity compared to the lipid productivity under only the $10-\mathrm{pH}$ condition.

The lipid content of H. pluvialis could also be increased by melatonin induction coupled with nitrogen deficiency and photoinduction at $150 \mu \mathrm{mol}$ photons. $\mathrm{m}^{-2} \cdot \mathrm{s}^{-1}$. The highest lipid content was $42.84 \%$ which was 1.22 -fold greater than that of the control samples (Ding et al., 2018). In Chlorella sp. BUM11008, the combined iron and potassium-phosphate deprivations leading to a substantial increase in lipid content of the cell with significant increase in linolenic acid and arachidic acid, which were the major PUFA and SFA of the fatty acid composition (Praveenkumar et al., 2012).

More recently, Song et al. (2020) have demonstrated that combined effect of nitrogen deficiency with strigolactone induction could increase the lipid content and lipid productivity in Monoraphidium sp. QLY-1. Authors observed that the jasmonic acid (JA) content was also increased rapidly under nitrogen deficiency with or without SL conditions. JA is generally regarded as an oxylipin signaling molecule that plays diverse functions in plants and microalgae especially in defense and stress responses. Authors suggested that the increased in lipid production may be related to the stimulation of JA synthesis under combined nitrogen deficiency and SL treatment in microalgae. An exogenous JA supplementation was tested and led to the highest lipid content $(57.12 \%)$ and productivity $\left(322.65 \mathrm{mg} . \mathrm{L}^{-1} . \mathrm{d}^{-1}\right)$ under nitrogen stress combined with SL treatment, validating the role of JA in regulating lipid synthesis and oxidative stress response in microalgae 
(Song et al., 2020). Also, Zhao et al. (2021) have demonstrated the effect of melatonin on lipid accumulation in Monoraphidium sp. QLY-1 under salinity stress. The melatonin induction significantly promoted the lipid content, which was 1.16 - and 1.44-fold higher than those induced by salinity stress alone and control, respectively.

Also, combined effect on growth and lipid accumulation has been recently demonstrated between nitrogen starvation and IAA on $N$. oceanica. A drastic decease of SFA associated to drastic increase of MUFA and PUFA were obtained with combined factors. These changes are more and more important as the concentration of IAA increases (Touliabah and Almutairi, 2021).

Very recently, Chen et al. (2020a) have chosen to use glycerol as a low-cost carbon source as well as an inexpensive nitrate source (corn steep liquor) to investigate the potential of Thraustochytrium sp. BM2 for cost-effective lipid production. Lipid content and productivity reached $76 \%$ and $37 \mathrm{mg} . \mathrm{L}^{-1} \cdot \mathrm{h}^{-1}$ when corn steep liquor and glycerol were used at $12.5 \mathrm{~g} . \mathrm{L}^{-1}$ and $10 \mathrm{~g} . \mathrm{L}^{-1}$, respectively. Lipid content could be further enhanced to $79 \%$ by addition of sea salt $(2 \% \mathrm{w} / \mathrm{v})$. Crude glycerol with acid and $\mathrm{CaCl}_{2}$ pretreatment enhanced the overall lipid productivity to $131 \mathrm{mg} \cdot \mathrm{L}^{-1} \cdot \mathrm{h}^{-1}$. A semicontinuous culture with harvesting of $50 \%$ of the microalgal culture every cycle allowed to enhanced overall lipid productivity to $158 \mathrm{mg} . \mathrm{L}^{-1} \cdot \mathrm{h}^{-1}$ (Chen et al., 2020b).

\subsection{Statistical approach}

Optimizing the microalgae biomass productivity through the optimization of different abiotic factors is one of the crucial improvements to increase lipid production. As it has been demonstrated, these optimal conditions are strain dependent.

Several studies have shown the benefit of using statistical models to optimize growth parameters. For example, Miranda et al. (2016) have used a simple $2^{3}$ factorial design combined with the Response surface methodology (RSM) in order to optimize nitrate, phosphate and salt concentrations to improve the lipid yield of Ankistrodesmus sp. and Chlamydomonas sp. Their results indicated significant interactions between the three factors for both biomass and lipid productivities, with a confidence level equal to $95 \%$ for the two species. The maximal biomass productivities for Ankistrodesmus sp. and Chlamydomonas sp. $\left(34 \mathrm{mg} . \mathrm{L}^{-1} \cdot \mathrm{d}^{-1}\right.$ and $90 \mathrm{mg} \cdot \mathrm{L}^{-1} \cdot \mathrm{d}^{-1}$, respectively) were achieved with concentrations of nitrate at 0.04 and $0.08 \mathrm{~g} . \mathrm{L}^{-1}$, phosphate at $0.02 \mathrm{~g} . \mathrm{L}^{-1}$ for both microalgae, with absence of sodium chloride for Ankistrodesmus sp. and independent level of sodium chloride for Chlamydomonas sp.

More recently, a Central Composite Face-centered (CCF) design with RSM were used to determine the optimum light intensity and $\mathrm{CO}_{2}$ concentration to obtain the best biomass and lipid productivity of Ettlia sp. YC001. Based on the model, the maximum biomass and lipid productivity were $28 \pm 1.5 \mathrm{~g} . \mathrm{m}^{-2}$.day ${ }^{-1}$ at $730 \mu \mathrm{E} \cdot \mathrm{m}^{-2} \cdot \mathrm{s}^{-1}$ with $8 \% \quad \mathrm{CO}_{2}$ concentration, and $4.2 \pm 0.3 \mathrm{~g} \cdot \mathrm{m}^{-2} \cdot \mathrm{day}^{-1}$ at $500 \mu \mathrm{E} \cdot \mathrm{m}^{-2} \cdot \mathrm{s}^{-1}$ with $7 \%$ of $\mathrm{CO}_{2}$ concentration (Kim et al., 2018).

In 2020, a wastewater isolated co-culture microalgae-yeast (CCMY) was evaluated as potential biomass and lipidsefficient producer. It was composed of Scenedesmus obliquus,
Scenedesmus sp. and a number of yeast species including Candida pimensis. A Box-Behnken Experimental Design (BBED) was applied to determine the best combination of nutrients and their effect on the biomass and lipids. They determined that the maximum lipid accumulation in CCMY was achieved when the sodium nitrate:potassium phosphate ratio is the smallest one and the potassium phosphate concentration is lower than ferrous sulfate concentration (Suastes-Rivas et al., 2020).

Usually, the number of variables in these statistical studies was restricted to a maximum of 3 . However, lipid productivity of microalgae is significantly affected by all aforementioned abiotic factor. A similar study using a three level Box-Behnken design was used to investigate the effect of six variables on lipid productivity and $\mathrm{CO}_{2}$ fixation of Chlorella protothecoides (Binnal and Babu, 2017). Fifty-four experiments and a statistical optimization was performed using RSM. The optimum were determined as follow: $\mathrm{pH}-6.51$, Temperature$28.63^{\circ} \mathrm{C}$, light intensity-5.31 klux, Photoperiod$15.36 \mathrm{~h}: 8.64 \mathrm{~h}, \mathrm{CO}_{2}$ concentration- $6.26 \%(\mathrm{v} / \mathrm{v})$ and aeration rate $-2.92 \mathrm{lpm}$. The highest lipid productivity and $\mathrm{CO}_{2}$ fixation under these conditions were $274.15 \mathrm{mg} \cdot \mathrm{L}^{-1} \cdot \mathrm{d}^{-1}$ and $273.66 \mathrm{mg} . \mathrm{L}^{-1} \cdot \mathrm{d}^{-1}$, respectively.

Finally, Chiranjeevi and Mohan (2016) have done a design of experimental methodology using Taguchi orthogonal array to evaluate the specific influence of eight important factors (light, $\mathrm{pH}$, temperature, carbon concentration, nitrates, phosphates, magnesium ion concentration and carbon source) on the biomass production. The relative influence of the abiotic factors has been classified as follows: Carbon $>$ Nitrates $>$ Light $>$ Temperature $>\mathrm{pH}>$ Carbon sources $>$ Magnesium $>$ Phosphates. In order to understand the influence of the interaction between the individual parameters, the authors assigned them a severity index (SI). The results showed significant interactions among the factors. Carbon concentration with nitrates showed highest SI (85.13\%), followed by temperature and light $(60.4 \%)$ then $\mathrm{pH}$ with magnesium (SI 59.3\%). The lowest SI was attributed to carbon concentration and light interaction (32.6\%). An analysis of variance (ANOVA) with the percentage of contribution of each factor in interaction have confirmed that carbon concentration as the most influential factor, accounting for $16.8 \%$ of the overall variance followed by nitrates $(12.8 \%)$ and light $(9.3 \%)$. At least, light, carbon concentration and nitrates contributed a majority of $38.9 \%$ at their individual levels on the microalgae biomass production indicating their critical role in the optimization.

\section{Conclusion and perspectives}

The production costs of biomass and lipids will depend on the considered systems (strain, environmental parameters and culture system). Some microalgae, called oleaginous microalgae, are able of producing larger quantities of fatty acids and must be favored for the production of biofuels. It is clear that different species react differently to different stresses by producing different fatty acids or by changing their biochemical composition. This review focused on how environmental factors can play an important role in improving lipid production in microalgae. Of all possible approaches, 
nitrogen deprivation appears to be applied most often. Changes in temperature, salt stress, appropriate concentration of metallic trace elements and supplementation of the medium with hormones can also induce lipid accumulation but seem more difficult to control in a large-scale culture system. The identification of other approaches such as the influence of $\mathrm{CO}_{2}$, the use of organic substrate, light intensity have also been studied in many species. Studies have shown that the optimization of these parameters by statistical or experimental methods makes it possible to significantly improve the lipid production, in particular through the increase in cell growth. However, the exact combination allowing optimal lipid productivity in a given culture system will be specific to each strain of microalgae. Further work is therefore required and recent advances have been made with the use of other approaches, such as the use of the neurotransmitter (Zhao et al., 2020), a pretreatment of atmospheric-pressure plasma (Almarashi et al., 2020), co-cultures with bacteria and filamentous fungi (Huo et al., 2020; Chu et al., 2021) and transgenic organisms (James et al., 2013; Han et al., 2020). 2-step hybrid systems including optimization of growth in a rich medium and then transfer of part of the culture under conditions favoring lipid production have also been developed (Aziz et al., 2020).

Li et al. (2019) has reported that the cost of microalgae production processes was strongly affected by the cost of the raw materials used. An alternative eco-friendly solution to reduce these costs could come from the use of wastewater as nutrient sources. According to Acién et al. (2012), the utilization of wastewater in the production of algal biodiesel could reduce the total production costs to $\$ 1.5 \mathrm{~kg}^{-1}$ and using flue gases from industrial sources can decrease the cost of microalgae production to $\$ 2.08 \mathrm{~kg}^{-1}$. To date, some types of wastewater rich in organic matter, such as piggery wastewater, municipal wastewater and monosodium glutamate wastewater have been successfully utilized for the mixotrophic cultivation of microalgae (Wang et al., 2010, 2012b; Ebrahimian et al., 2014; Aketo et al., 2020). Recent work has highlighted methods that can improve lipid production in microalgae cultivated with wastewater (Gao et al., 2019; Tan et al., 2020). Finally, Ren et al. (2019) have shown that ultrasonic irradiation could be a promising process to significantly enhance the lipid production by microalgae cultivated in a non-sterile domestic wastewater. From this point of view, the use of wastewater to produce biofuels from microalgae appears to be a cost-friendly and eco-responsible alternative solution since it contributes to the pollutants removal and recycling of water.

Although there is extensive literature on the impact of different abiotic factors taken independently of each other, studies have shown that the co-optimization of these parameters by statistical or experimental methods are future avenues with a view to improve lipid production. However, the optimization of growth associate to culture factors alone remains insufficient to reach profitability thresholds, particularly for applications in the field of biofuels. For this, it is necessary to take into account in its entirety the entire production process and improve all stages. This includes the optimization of the culture parameters, but also the choice in the culture technology (photobioreactor), the method of harvesting and separating the biomass with the culture medium, the extraction of the target compounds, as well as the purification step and that of any biochemical modifications to convert the molecules into biodiesel.

\section{Declaration of competing interest}

The authors declare that they have no known competing financial interests or personal relationships that could have appeared to influence the work reported in this paper.

Acknowledgment. The authors acknowledge the Occitanie Region for its financial support through its regional development fund FEDER/ERDF (GREENALG project).

\section{References}

Abomohra AE-F, Shang H, El-Sheekh M, et al. 2019. Night illumination using monochromatic light-emitting diodes for enhanced microalgal growth and biodiesel production. Bioresour Technol 288: 121514. https://doi.org/10.1016/j.bio rtech.2019.121514.

Acién FG, Fernández JM, Magán JJ, Molina E. 2012. Production cost of a real microalgae production plant and strategies to reduce it. Biotechnol Adv, Special Issue on ACB 2011(30): 1344-1353. https://doi.org/10.1016/j.biotechadv.2012.02.005.

Aguilera-Sáez LM, Abreu AC, Camacho-Rodríguez J, et al. 2019. NMR metabolomics as an effective tool to unravel the effect of light intensity and temperature on the composition of the marine microalgae Isochrysis galbana. J Agric Food Chem 67: 38793889. https://doi.org/10.1021/acs.jafc.8b06840.

Aketo T, Hoshikawa Y, Nojima D, et al. 2020. Selection and characterization of microalgae with potential for nutrient removal from municipal wastewater and simultaneous lipid production. $J$ Biosci Bioeng 129: 565-572. https://doi.org/10.1016/j. jbiosc.2019.12.004.

Almarashi JQM, El-Zohary SE, Ellabban MA, Abomohra AE-F. 2020. Enhancement of lipid production and energy recovery from the green microalga Chlorella vulgaris by inoculum pretreatment with low-dose cold atmospheric pressure plasma (CAPP). Energy Convers Manag 204: 112314. https://doi.org/10.1016/j.encon man.2019.112314.

Amini Khoeyi Z, Seyfabadi J, Ramezanpour Z. 2012. Effect of light intensity and photoperiod on biomass and fatty acid composition of the microalgae, Chlorella vulgaris. Aquacult Int 20: 41-49. https://doi.org/10.1007/s10499-011-9440-1.

An M, Gao L, Zhao W, Chen W, Li M. 2020. Effects of nitrogen forms and supply mode on lipid production of microalga Scenedesmus obliquus. Energies 13: 697. https://doi.org/10.3390/en13030697.

Arora N, Patel A, Mehtani J, Pruthi PA, Pruthi V, Poluri KM. 2019. Co-culturing of oleaginous microalgae and yeast: Paradigm shift towards enhanced lipid productivity. Environ Sci Pollut Res 26: 16952-16973. https://doi.org/10.1007/s11356-019-05138-6.

Aziz MMA, Kassim KA, Shokravi Z, et al. 2020. Two-stage cultivation strategy for simultaneous increases in growth rate and lipid content of microalgae: A review. Renew Sustain Energy Rev 119: 109621. https://doi.org/10.1016/j.rser.2019.109621.

Binnal P, Babu PN. 2017. Statistical optimization of parameters affecting lipid productivity of microalga Chlorella protothecoides cultivated in photobioreactor under nitrogen starvation. South Afr $J$ Chem Eng 23: 26-37. https://doi.org/10.1016/j. sajce.2017.01.001.

Cao J, Yuan H, Li B, Yang J. 2014. Significance evaluation of the effects of environmental factors on the lipid accumulation of 
Chlorella minutissima UTEX 2341 under low-nutrition heterotrophic condition. Bioresour Technol 152: 177-184. https://doi. org/10.1016/j.biortech.2013.10.084.

Chen YH, Walker TH. 2012. Fed-batch fermentation and supercritical fluid extraction of heterotrophic microalgal Chlorella protothecoides lipids. Bioresour Technol 114: 512-517.

Chen G-Q, Jiang Y, Chen F. 2008. Salt-induced alterations in lipid composition of diatom Nitzschia laevis (Bacillariophyceae) under heterotrophic culture condition. J Phycol 44: 1309-1314. https:// doi.org/10.1111/j.1529-8817.2008.00565.x.

Chen C-Y, Lee M-H, Dong C-D, Leong YK, Chang J-S. 2020a. Enhanced production of microalgal lipids using a heterotrophic marine microalga Thraustochytrium sp. BM2. Biochem Eng $J$ 154: 107429. https://doi.org/10.1016/j.bej.2019.107429.

Chen C-Y, Lee M-H, Leong YK, Chang J-S, Lee D-J. $2020 \mathrm{~b}$. Biodiesel production from heterotrophic oleaginous microalga Thraustochytrium sp. BM2 with enhanced lipid accumulation using crude glycerol as alternative carbon source. Bioresour Technol 306: 123113. https://doi.org/10.1016/j.bio rtech.2020.123113.

Chi Z, Pyle D, Wen Z, Frear C, Chen S. 2007. A laboratory study of producing docosahexaenoic acid from biodiesel-waste glycerol by microalgal fermentation. Process Biochem 42: 1537-1545. https://doi.org/10.1016/j.procbio.2007.08.008.

Chiranjeevi P, Mohan SV. 2016. Critical parametric influence on microalgae cultivation towards maximizing biomass growth with simultaneous lipid productivity. Renew Energy 98: 64-71. https:// doi.org/10.1016/j.renene.2016.03.063.

Chiu S-Y, Kao C-Y, Tsai M-T, Ong S-C, Chen C-H, Lin C-S. 2009. Lipid accumulation and $\mathrm{CO}_{2}$ utilization of Nannochloropsis oculata in response to $\mathrm{CO}_{2}$ aeration. Bioresour Technol 100: 833838. https://doi.org/10.1016/j.biortech.2008.06.061.

Cho D-H, Ramanan R, Heo J, et al. 2015. Enhancing microalgal biomass productivity by engineering a microalgal-bacterial community. Bioresour Technol 175: 578-585. https://doi.org/ 10.1016/j.biortech.2014.10.159.

Choi H-J, Yu S-W. 2015. Influence of crude glycerol on the biomass and lipid content of microalgae. Biotechnol Biotechnol Equip 29: 506-513. https://doi.org/10.1080/13102818.2015.1013988.

Chu F, Cheng J, Zhang X, Ye Q, Zhou J. 2019. Enhancing lipid production in microalgae Chlorella PY-ZU1 with phosphorus excess and nitrogen starvation under $15 \% \mathrm{CO}_{2}$ in a continuous two-step cultivation process. Chem Eng J 375: 121912. https:// doi.org/10.1016/j.cej.2019.121912.

Chu R, Li S, Zhu L, et al. 2021. A review on co-cultivation of microalgae with filamentous fungi: Efficient harvesting, wastewater treatment and biofuel production. Renew Sustain Energy Rev 139: 110689. https://doi.org/10.1016/j.rser.2020.110689.

Ding W, Zhao Y, Xu J-W, et al. 2018. Melatonin: A multifunctional molecule that triggers defense responses against high light and nitrogen starvation stress in Haematococcus pluvialis. J Agric Food Chem 66: 7701-7711. https://doi.org/10.1021/acs.jafc.8b02178.

Duan X, Ren GY, Liu LL, Zhu WX. 2012. Salt-induced osmotic stress for lipid overproduction in batch culture of Chlorella vulgaris. Afr J Biotechnol 11: 7072-7078. https://doi.org/10.4314/ajb.v11i27.

Ebrahimian A, Kariminia H-R, Vosoughi M. 2014. Lipid production in mixotrophic cultivation of Chlorella vulgaris in a mixture of primary and secondary municipal wastewater. Renew Energy 71: 502-508. https://doi.org/10.1016/j.renene.2014.05.031.

Esakkimuthu S, Krishnamurthy V, Wang S, Hu X, Swaminathan K, Abomohra AE-F. 2020. Application of p-coumaric acid for extraordinary lipid production in Tetradesmus obliquus: A sustainable approach towards enhanced biodiesel production.
Renew Energy 157: 368-376. https://doi.org/10.1016/j. renene.2020.05.005

Feng P, Deng Z, Fan L, Hu Z. 2012. Lipid accumulation and growth characteristics of Chlorella zofingiensis under different nitrate and phosphate concentrations. J Biosci Bioeng 114: 405-410. https:// doi.org/10.1016/j.jbiosc.2012.05.007.

Gao F, Yang H-L, Li C, et al. 2019. Effect of organic carbon to nitrogen ratio in wastewater on growth, nutrient uptake and lipid accumulation of a mixotrophic microalgae Chlorella sp. Bioresour Technol 282: 118-124. https://doi.org/10.1016/j.bio rtech.2019.03.011.

Gim GH, Ryu J, Kim MJ, Kim PI, Kim SW. 2016. Effects of carbon source and light intensity on the growth and total lipid production of three microalgae under different culture conditions. $J$ Ind Microbiol Biotechnol 43: 605-616. https://doi.org/10.1007/ s10295-016-1741-y.

Gupta S, Pawar SB. 2018. Mixotrophic cultivation of microalgae to enhance the quality of lipid for biodiesel application: effects of scale of cultivation and light spectrum on reduction of $\alpha$-linolenic acid. Bioprocess Biosyst Eng 41: 531-542. https://doi.org/ 10.1007/s00449-017-1888-6.

Han X, Song X, Li F, Lu Y. 2020. Improving lipid productivity by engineering a control-knob gene in the oleaginous microalga Nannochloropsis oceanica. Metab Eng Commun 11: e00142. https://doi.org/10.1016/j.mec.2020.e00142.

Higgins BT, VanderGheynst JS. 2014. Effects of Escherichia coli on mixotrophic growth of Chlorella minutissima and production of biofuel precursors. PLOS ONE 9: e96807. https://doi.org/ 10.1371/journal.pone.0096807.

Higgins BT, Gennity I, Samra S, Kind T, Fiehn O, VanderGheynst JS. 2016. Cofactor symbiosis for enhanced algal growth, biofuel production, and wastewater treatment. Algal Res 17: 308-315. https://doi.org/10.1016/j.algal.2016.05.024.

Ho S-H, Chen W-M, Chang J-S. 2010. Scenedesmus obliquus CNW$\mathrm{N}$ as a potential candidate for $\mathrm{CO}_{2}$ mitigation and biodiesel production. Bioresour Technol 101: 8725-8730. https://doi.org/ 10.1016/j.biortech.2010.06.112.

Hoffmann M, Marxen K, Schulz R, Vanselow KH. 2010. TFA and EPA productivities of Nannochloropsis salina influenced by temperature and nitrate stimuli in turbidostatic controlled experiments. Mar Drugs 8: 2526-2545. https://doi.org/10.3390/ md8092526.

Hsieh C-H, Wu W-T. 2009. Cultivation of microalgae for oil production with a cultivation strategy of urea limitation. Bioresour Technol 100: 3921-3926. https://doi.org/10.1016/j. biortech.2009.03.019.

Huo S, Basheer S, Liu F, et al. 2020. Bacterial intervention on the growth, nutrient removal and lipid production of filamentous oleaginous microalgae Tribonema sp. Algal Res 52: 102088. https://doi.org/10.1016/j.algal.2020.102088.

James GO, Hocart CH, Hillier W, Price GD, Djordjevic MA. 2013. Temperature modulation of fatty acid profiles for biofuel production in nitrogen deprived Chlamydomonas reinhardtii. Bioresour Technol 127: 441-447. https://doi.org/10.1016/j.bio rtech.2012.09.090.

Janssen M, de Winter M, Tramper J, Mur LR, Snel J, Wijffels RH. 2000. Efficiency of light utilization of Chlamydomonas reinhardtii under medium-duration light/dark cycles. J Biotechnol 78: 123-137. https://doi.org/10.1016/s0168-1656(99)00233-3.

Jiang H, Gao K. 2004. Effects of lowering temperature during culture on the production of polyunsaturated fatty acids in the marine diatom Phaeodactylum Tricornutum (Bacillariophyceae) 1. J Phycol 40: 651-654. https://doi.org/10.1111/j.1529-8817.2004.03112.x. 
Jiang L, Pei H, Hu W, Han F, Zhang L, Hou Q. 2015. Effect of diethyl aminoethyl hexanoate on the accumulation of high-value biocompounds produced by two novel isolated microalgae. Bioresour Technol 197: 178-184. https://doi.org/10.1016/j.bio rtech.2015.08.068.

Ju J-H, Ko D-J, Heo S-Y, et al. 2020. Regulation of lipid accumulation using nitrogen for microalgae lipid production in Schizochytrium sp. A BC101. Renew Energy 153: 580-587. https://doi.org/ 10.1016/j.renene.2020.02.047.

Kaewkannetra P, Enmak P, Chiu T. 2012. The effect of $\mathrm{CO}_{2}$ and salinity on the cultivation of Scenedesmus obliquus for biodiesel production. Biotechnol Bioproc E 17: 591-597. https://doi.org/ 10.1007/s12257-011-0533-5.

Kang NK, Lee B, Choi G-G, et al. 2014. Enhancing lipid productivity of Chlorella vulgaris using oxidative stress by $\mathrm{TiO}_{2}$ nanoparticles. Korean J Chem Eng 31: 861-867. https://doi.org/10.1007/ s11814-013-0258-6.

Khotimchenko SV, Yakovleva IM. 2005. Lipid composition of the red alga Tichocarpus crinitus exposed to different levels of photon irradiance. Phytochemistry 66: 73-79. https://doi.org/10.1016/j. phytochem.2004.10.024.

Khozin-Goldberg I, Cohen Z. 2006. The effect of phosphate starvation on the lipid and fatty acid composition of the fresh water eustigmatophyte Monodus subterraneus. Phytochemistry 67: 696-701. https://doi.org/10.1016/j.phytochem.2006.01.010.

Kim S, Moon M, Kwak M, Lee B, Chang YK. 2018. Statistical optimization of light intensity and $\mathrm{CO}_{2}$ concentration for lipid production derived from attached cultivation of green microalga Ettlia sp. Sci Rep 8: 15390. https://doi.org/10.1038/s41598-01833793-1.

Kwak HS, Kim JYH, Woo HM, Jin E, Min BK, Sim SJ. 2016. Synergistic effect of multiple stress conditions for improving microalgal lipid production. Algal Res 19: 215-224. https://doi. org/10.1016/j.algal.2016.09.003.

Lakshmikandan M, Murugesan AG, Wang S, Abomohra AE-F, Jovita PA, Kiruthiga S. 2020. Sustainable biomass production under $\mathrm{CO}_{2}$ conditions and effective wet microalgae lipid extraction for biodiesel production. J Clean Prod 247: 119398. https://doi.org/ 10.1016/j.jclepro.2019.119398.

Lakshmikandan M, Wang S, Murugesan AG, Saravanakumar M, Selvakumar G. 2021. Co-cultivation of Streptomyces and microalgal cells as an efficient system for biodiesel production and bioflocculation formation. Bioresour Technol 332: 125118. https://doi.org/10.1016/j.biortech.2021.125118.

Li Y, Mu J, Chen D, et al. 2013. Production of biomass and lipid by the microalgae Chlorella protothecoides with heterotrophic- $\mathrm{Cu}$ (II) stressed (HCuS) coupling cultivation. Bioresour Technol 148: 283-292. https://doi.org/10.1016/j.biortech.2013.08.153.

Li D, Amoah PK, Chen B, et al. 2019. Feasibility of growing Chlorella sorokiniana on cooking cocoon wastewater for biomass production and nutrient removal. Appl Biochem Biotechnol 188: 663-676. https://doi.org/10.1007/s12010-018-02942-7.

Liu Z-Y, Wang G-C, Zhou B-C. 2008. Effect of iron on growth and lipid accumulation in Chlorella vulgaris. Bioresour Technol, Explor Horizons Biotechnol: Glob Venture 99: 4717-4722. https://doi.org/10.1016/j.biortech.2007.09.073.

Lv J-M, Cheng L-H, Xu X-H, Zhang L, Chen H-L. 2010. Enhanced lipid production of Chlorella vulgaris by adjustment of cultivation conditions. Bioresour Technol 101: 6797-6804. https://doi.org/10.1016/j.biortech.2010.03.120.

Mandotra SK, Kumar P, Suseela MR, Nayaka S, Ramteke PW. 2016. Evaluation of fatty acid profile and biodiesel properties of microalga Scenedesmus abundans under the influence of phosphorus, $\mathrm{pH}$ and light intensities. Bioresour Technol 201: 222-229. https://doi.org/10.1016/j.biortech.2015.11.042.

Miranda CT, de Lima DVN, Atella GC, de Aguiar PF, Azevedo SMFO. 2016. Optimization of nitrogen, phosphorus and salt for lipid accumulation of microalgae: Towards the viability of microalgae biodiesel. Nat Sci 8: 557-573. https://doi.org/ 10.4236/ns.2016.812055.

Norman HA, Thompson GA. 1985. Effects of low-temperature stress on the metabolism of phosphatidylglycerol molecular species in Dunaliella salina. Arch Biochem Biophys 242: 168-175. https:// doi.org/10.1016/0003-9861(85)90490-4.

Nzayisenga JC, Farge X, Groll SL, Sellstedt A. 2020. Effects of light intensity on growth and lipid production in microalgae grown in wastewater. Biotechnol Biofuels 13: 4. https://doi.org/10.1186/ s13068-019-1646-x.

Ogawa T, Ogren WL. 1985. Action spectra for accumulation of inorganic carbon in the cyanobacterium, Anabaena variabilis. Photochem Photobiol 41: 583-587. https://doi.org/10.1111/ j.1751-1097.1985.tb03530.x.

Ortiz Montoya EY, Casazza AA, Aliakbarian B, Perego P, Converti A, de Carvalho JCM. 2014. Production of Chlorella vulgaris as a source of essential fatty acids in a tubular photobioreactor continuously fed with air enriched with $\mathrm{CO}_{2}$ at different concentrations. Biotechnol Prog 30: 916-922. https://doi.org/ 10.1002/btpr.1885.

Pal D, Khozin-Goldberg I, Cohen Z, Boussiba S. 2011. The effect of light, salinity, and nitrogen availability on lipid production by Nannochloropsis sp. Appl Microbiol Biotechnol 90: 1429-1441. https://doi.org/10.1007/s00253-011-3170-1.

Park J, Park BS, Wang P, et al. 2017. Phycospheric native bacteria Pelagibaca bermudensis and Stappia sp. ameliorate biomass productivity of Tetraselmis striata (KCTC1432BP) in cocultivation system through mutualistic interaction. Front Plant Sci 8: 289. https://doi.org/10.3389/fpls.2017.00289.

Praveenkumar R, Shameera K, Mahalakshmi G, Akbarsha MA, Thajuddin N. 2012. Influence of nutrient deprivations on lipid accumulation in a dominant indigenous microalga Chlorella $\mathrm{sp}$, BU M11008: Evaluation for biodiesel production. Biomass Bioenergy 37: 60-66. https://doi.org/10.1016/j.bio mbioe.2011.12.035.

Pyle DJ, Garcia RA, Wen Z. 2008. Producing docosahexaenoic acid (DHA)-rich algae from biodiesel-derived crude glycerol: Effects of impurities on DHA production and algal biomass composition. J Agric Food Chem 56: 3933-3939. https://doi.org/10.1021/ jf800602s.

Ra C-H, Kang C-H, Jung J-H, Jeong G-T, Kim S-K. 2016. Effects of light-emitting diodes (LEDs) on the accumulation of lipid content using a two-phase culture process with three microalgae. Bioresour Technol 212: 254-261. https://doi.org/10.1016/j.bio rtech.2016.04.059.

Rai V, Muthuraj M, Gandhi MN, Das D, Srivastava S. 2017. Realtime iTRAQ-based proteome profiling revealed the central metabolism involved in nitrogen starvation induced lipid accumulation in microalgae. Sci Rep 7: 45732. https://doi.org/ 10.1038/srep45732.

Rajvanshi M, Shankar Sagaram S. 2019. Sustainable downstream processing of microalgae for industrial application. CRC Press.

Ren H-Y, Liu B-F, Kong F, Zhao L, Xie G-J, Ren N-Q. 2014. Enhanced lipid accumulation of green microalga Scenedesmus sp. by metal ions and EDTA addition. Bioresour Technol 169: 763767. https://doi.org/10.1016/j.biortech.2014.06.062.

Ren H-Y, Zhu J-N, Kong F, et al. 2019. Ultrasonic enhanced simultaneous algal lipid production and nutrients removal from 
non-sterile domestic wastewater. Energy Convers Manag 180: 680-688. https://doi.org/10.1016/j.enconman.2018.11.028.

Sakurai T, Aoki M, Ju X, et al. 2016. Profiling of lipid and glycogen accumulations under different growth conditions in the sulfothermophilic red alga Galdieria sulphuraria. Bioresour Technol 200: 861-866. https://doi.org/10.1016/j.biortech.2015.11.014.

Salama E-S, Jeon B-H, Chang SW, et al. 2017. Interactive effect of indole-3-acetic acid and diethyl aminoethyl hexanoate on the growth and fatty acid content of some microalgae for biodiesel production. J Clean Prod 168: 1017-1024. https://doi.org/ 10.1016/j.jclepro.2017.09.057.

Sato A, Matsumura R, Hoshino N, Tsuzuki M, Sato N. 2014. Responsibility of regulatory gene expression and repressed protein synthesis for triacylglycerol accumulation on sulfurstarvation in Chlamydomonas reinhardtii. Front Plant Sci 5. https://doi.org/10.3389/fpls.2014.00444.

Singh J, Jain D, Agarwal P, Singh RP. 2020. Auxin and cytokinin synergism augmenting biomass and lipid production in microalgae Desmodesmus sp. JS07. Process Biochem 95: 223-234. https://doi.org/10.1016/j.procbio.2020.02.012.

Solovchenko AE, Khozin-Goldberg I, Didi-Cohen S, Cohen Z, Merzlyak MN. 2008. Effects of light intensity and nitrogen starvation on growth, total fatty acids and arachidonic acid in the green microalga Parietochloris incisa. J Appl Phycol 20: 245251. https://doi.org/10.1007/s10811-007-9233-0.

Song X, Zhao Y, Li T, et al. 2019. Enhancement of lipid accumulation in Monoraphidium sp. QLY-1 by induction of strigolactone. Bioresour Technol 288: 121607. https://doi.org/10.1016/j.bio rtech.2019.121607.

Song X, Zhao Y, Han B, et al. 2020. Strigolactone mediates jasmonic acid-induced lipid production in microalga Monoraphidium sp. QLY-1 under nitrogen deficiency conditions. Bioresour Technol 306: 123107. https://doi.org/10.1016/j.biortech.2020.123107.

Spalding MH, Critchley C, Govindjee, Orgren WL. 1984. Influence of carbon dioxide concentration during growth on fluorescence induction characteristics of the Green Alga Chlamydomonas reinhardii. Photosynth Res 5: 169-176. https://doi.org/10.1007/ BF00028529.

Suastes-Rivas JK, Hernández-Altamirano R, Mena-Cervantes VY, Chairez I. 2020. Simultaneous optimization of biomass and metabolite production by a microalgae-yeast co-culture under inorganic micronutrients. Bioenergy Res 13: 974-985. https://doi. org/10.1007/s12155-020-10116-9.

Sun X, Cao Y, Xu H, et al. 2014. Effect of nitrogen-starvation, light intensity and iron on triacylglyceride/carbohydrate production and fatty acid profile of Neochloris oleoabundans HK-129 by a two-stage process. Bioresour Technol 155: 204-212. https://doi. org/10.1016/j.biortech.2013.12.109.

Takagi M, Karseno, Yoshida T. 2006. Effect of salt concentration on intracellular accumulation of lipids and triacylglyceride in marine microalgae Dunaliella cells. J Biosci Bioeng 101: 223-226. https://doi.org/10.1263/jbb.101.223.

Tan X-B, Yang L-B, Zhang W-W, Zhao X-C. 2020. Lipids production and nutrients recycling by microalgae mixotrophic culture in anaerobic digestate of sludge using wasted organics as carbon source. Bioresour Technol 297: 122379. https://doi.org/10.1016/j. biortech.2019.122379.

Touliabah HE-S, Almutairi AW. 2021. Effect of phytohormones supplementation under nitrogen depletion on biomass and lipid production of Nannochloropsis oceanica for integrated application in nutrition and biodiesel. Sustainability 13: 592. https://doi. org/10.3390/su13020592.
Tsuzuki M, Ohnuma E, Sato N, Takaku T, Kawaguchi A. 1990. Effects of $\mathrm{CO}_{2}$ concentration during growth on fatty acid composition in microalgae 1. Plant Physiol 93: 851-856.

Udayan A, Sabapathy H, Arumugam M. 2020. Stress hormones mediated lipid accumulation and modulation of specific fatty acids in Nannochloropsis oceanica CASA CC201. Bioresour Technol 310: 123437. https://doi.org/10.1016/j.bio rtech.2020.123437.

Wan M, Jin X, Xia J, et al. 2014. The effect of iron on growth, lipid accumulation, and gene expression profile of the freshwater microalga Chlorella sorokiniana. Appl Microbiol Biotechnol 98: 9473-9481. https://doi.org/10.1007/s00253-014-6088-6.

Wang L, Min M, Li Y, et al. 2010. Cultivation of green algae Chlorella sp. in different wastewaters from municipal wastewater treatment plant. Appl Biochem Biotechnol 162: 1174-1186. https://doi.org/ 10.1007/s12010-009-8866-7.

Wang S-T, Pan Y-Y, Liu C-C, Chuang L-T, Chen C-NN. 2011. Characterization of a green microalga UTEX 2219-4: Effects of photosynthesis and osmotic stress on oil body formation. Bot Stud 52: 305-312.

Wang H, Fu R, Pei G. 2012a. A study on lipid production of the mixotrophic microalgae Phaeodactylum tricornutum on various carbon sources. Afr J Microbiol Res 6. https://doi.org/10.5897/ AJMR11.1365.

Wang H, Xiong H, Hui Z, Zeng X. 2012b. Mixotrophic cultivation of Chlorella pyrenoidosa with diluted primary piggery wastewater to produce lipids. Bioresour Technol 104: 215-220. https://doi. org/10.1016/j.biortech.2011.11.020.

Wei L, Huang X, Huang Z. 2015. Temperature effects on lipid properties of microalgae Tetraselmis subcordiformis and Nannochloropsis oculata as biofuel resources. Chin J Ocean Limnol 33: 99-106. https://doi.org/10.1007/s00343-015-3346-0.

Wei Z, Wang H, Li X, et al. 2020. Enhanced biomass and lipid production by co-cultivation of Chlorella vulgaris with Mesorhizobium sangaii under nitrogen limitation. J Appl Phycol 32: 233-242. https://doi.org/10.1007/s10811-019-01924-4.

Xie Z, Lin W, Luo J. 2021. Co-cultivation of microalga and xylanolytic bacterium by a continuous two-step strategy to enhance algal lipid production. Bioresour Technol 330: 124953. https://doi.org/10.1016/j.biortech.2021.124953.

Xin L, Hong-ying H, Jia Y. 2010a. Lipid accumulation and nutrient removal properties of a newly isolated freshwater microalga, Scenedesmus sp. LX1, growing in secondary effluent. New Biotechnology, Special Issue on Biocatalysis and Agricultural Biotechnology 27(3): 59-63. https://doi.org/10.1016/j. nbt.2009.11.006.

Xin L, Hong-ying H, Ke G, Ying-Xue S. 2010b. Effects of different nitrogen and phosphorus concentrations on the growth, nutrient uptake, and lipid accumulation of a freshwater microalga Scenedesmus sp. Bioresour Technol 101: 5494-5500. https:// doi.org/10.1016/j.biortech.2010.02.016.

Xin L, Hong-Ying H, Yu-Ping Z. 2011. Growth and lipid accumulation properties of a freshwater microalga Scenedesmus sp. under different cultivation temperature. Bioresour Technol 102: 3098-3102. https://doi.org/10.1016/j.biortech.2010.10.055.

Yang H, He Q, Rong J, Xia L, Hu C. 2014. Rapid neutral lipid accumulation of the alkali-resistant oleaginous Monoraphidium dybowskii LB50 by NaCl induction. Bioresour Technol 172: 131137. https://doi.org/10.1016/j.biortech.2014.08.066.

Yang J, Cao J, Xing G, Yuan H. 2015. Lipid production combined with biosorption and bioaccumulation of cadmium, copper, manganese and zinc by oleaginous microalgae Chlorella 
minutissima UTEX2341. Bioresour Technol 175: 537-544. https://doi.org/10.1016/j.biortech.2014.10.124.

Yeesang C, Cheirsilp B. 2011. Effect of nitrogen, salt, and iron content in the growth medium and light intensity on lipid production by microalgae isolated from freshwater sources in Thailand. Bioresour Technol 102: 3034-3040. https://doi.org/10.1016/j.bio rtech.2010.10.013.

Yeh K-L, Chang J-S. 2012. Effects of cultivation conditions and media composition on cell growth and lipid productivity of indigenous microalga Chlorella vulgaris ESP-31. Bioresour Technol 105: 120-127. https://doi.org/10.1016/j.biortech.2011.11.103.

Yilancioglu K, Cokol M, Pastirmaci I, Erman B, Cetiner S. 2014. Oxidative stress is a mediator for increased lipid accumulation in a newly isolated Dunaliella salina strain. PLOS ONE 9: e91957. https://doi.org/10.1371/journal.pone.0091957.

Yoo C, Jun S-Y, Lee J-Y, Ahn C-Y, Oh H-M. 2010. Selection of microalgae for lipid production under high levels carbon dioxide.
Bioresour Technol, Supplement Issue on Recent Developments of Biomass Conversion Technologies 101: S71-S74. https://doi.org/ 10.1016/j.biortech.2009.03.030.

Zhao Y, Song X, Zhong D, Yu L, Yu X. 2020. $\gamma$-Aminobutyric acid (GABA) regulates lipid production and cadmium uptake by Monoraphidium sp. QLY-1 under cadmium stress. Bioresour Technol 297: 122500. https://doi.org/10.1016/j.bio rtech.2019.122500.

Zhao Y, Song X, Zhao P, Li T, Xu J-W, Yu X. 2021. Role of melatonin in regulation of lipid accumulation, autophagy and salinityinduced oxidative stress in microalga Monoraphidium sp. QLY-1. Algal Res 54: 102196. https://doi.org/10.1016/j.al gal.2021.102196.

Zhu S, Huang W, Xu J, Wang Z, Xu J, Yuan Z. 2014. Metabolic changes of starch and lipid triggered by nitrogen starvation in the microalga Chlorella zofingiensis. Bioresour Technol 152: 292298. https://doi.org/10.1016/j.biortech.2013.10.092.

Cite this article as: Gaignard C, Zissis G, Buso D. 2021. Influence of different abiotic factors on lipid production by microalgae-a review. OCL 28: 57. 